\title{
1 Volcanologists - Who are we and where are we going?
}

2 Janine L. Kavanagh ${ }^{1 *}$, Catherine J. Annen², Steffi Burchardt ${ }^{3}$, Caitlin Chalk ${ }^{1}$, Elisabeth Gallant ${ }^{4,5}$, Julie

3 Morin $^{4}$, Jazmin Scarlett ${ }^{6}$, Rebecca Williams ${ }^{7}$

4 1. She/her. School of Environmental Sciences, University of Liverpool, Liverpool L69 3GP, UK

52 2. She/her. Institute of Geophysics, Czech Academy of Sciences, Prague 4, Czechia

6 3. She/her. Department of Earth Sciences, Uppsala University, Uppsala, Sweden

7 4. She/her. Department of Geography, University of Cambridge, Cambridge CB2 3EN, UK

8 5. USGS Hawaiian Volcano Observatory, Hilo, HI, 96720, USA

9 6. She/her. Independent Researcher

10 7. She/her. Department of Geography, Geology and Environment, University of Hull, Hull, UK

11 *corresponding author: Janine.Kavanagh@liverpool.ac.uk 
13 Equality, diversity and inclusivity (EDI) are principles all scientific groups and organisations should

14 strive to achieve as they secure working conditions, policies and practices that not only promote 15 high-quality scientific output but also well-being in their communities. In this article, we reflect on the progress of EDI in volcanology by presenting data related to memberships of international 17 volcanology organisations, positions on volcanology committees, volcanology awards and lead18 authorship on volcanology papers. The sparse demographic data available means our analysis 19 focuses mainly on gender identity discrimination, but we also show that discrimination related to 20 ethnicity, sexual orientation, religion, physical ability and socio-economic background is also 21 occurring, with the intersection of these discriminations further exacerbating marginalisation within 22 the volcanology community. We share suggestions and recommendations from other disciplines on 23 how individuals, research groups and organisations can promote, develop, and implement new 24 initiatives to call out and tackle discrimination and advance EDI in the volcanological community. 


\section{Introduction}

There is a well-documented diversity crisis in geoscience (Bernard and Cooperdock, 2018; Dowey et al., 2021; Dutt, 2020; Marin-Spiotta et al., 2020). To date, no international study has focused on equality, diversity and inclusion (EDI) in volcanology. Therefore, our perspective must present new data, raise awareness about the experiences of members of our community, and recommend how individuals and organisations should move EDI forwards in volcanology.

We analyse memberships of international organisations, positions on prestigious committees, award winners, and lead-authors of publications. We have collated over 100 anonymous stories from volcanologists, which collectively describe a culture in volcanology that requires immediate change. Some accounts of witnessed and experienced discrimination are harrowing and some comments readers may find distressing or offensive (see full transcripts of stories in the Supplementary Materials).

\section{Who is the volcanology community?}

The only data available to explore who the volcanology community is today come from membership data collected by international organisations with a focus on volcanology (for data and methods, see Supplementary Materials). We are limited by the categories these organisations use to collect data on gender, and by the lack of data on other demographics and protected characteristics ${ }^{1}$.

The International Association of Volcanology and Chemistry of the Earth's Interior (IAVCEI) is part of the International Union of Geodesy and Geophysics (IUGG). Its organisational structures, volcanology focus and international affiliation makes for an interesting comparison to volcanology

\footnotetext{
${ }^{1}$ Whilst these vary by country, the international human rights legal framework contains international instruments to combat specific forms of discrimination, including discrimination against indigenous peoples, migrants, minorities, people with disabilities, discrimination against women, racial and religious discrimination, or discrimination based on sexual orientation and gender identity.
} 
groups that are regional (e.g. Engwell et al., 2020) or only include some aspects of volcanology, such as the American Geophysical Union (AGU) Volcanology, Geochemistry \& Petrology (VGP) Section or the European Geosciences Union (EGU) Geochemistry-Mineralogy-Petrology-Volcanology (GMPV) Division.

The IAVCEI 2021 membership data reports only the geographical location of the membership and the gender identity (either male or female must be selected during registration, Figure 1). In 2021 IAVCEI had 937 members (39\% female, 61\% male) across 62 countries (See Table 1). The overwhelming majority of countries around the world have more male than female IAVCEI members, and only three countries with $>4$ members have close to $50 \%$ female members (the UK, New Zealand, Mexico) . A few countries have more females (e.g. Portugal, Denmark, the Philippines, Taiwan, Singapore, Brazil, Russia, Canada), and some countries have notably high male percentages (e.g. Japan, South Korea, France, Ecuador, Peru). Across Africa, the Middle East and India IAVCEI members are few and all male.

\section{IAVCEI membership and gender distribution in 2021}

Points are coloured according to the gender distribution. The size denotes the total members.

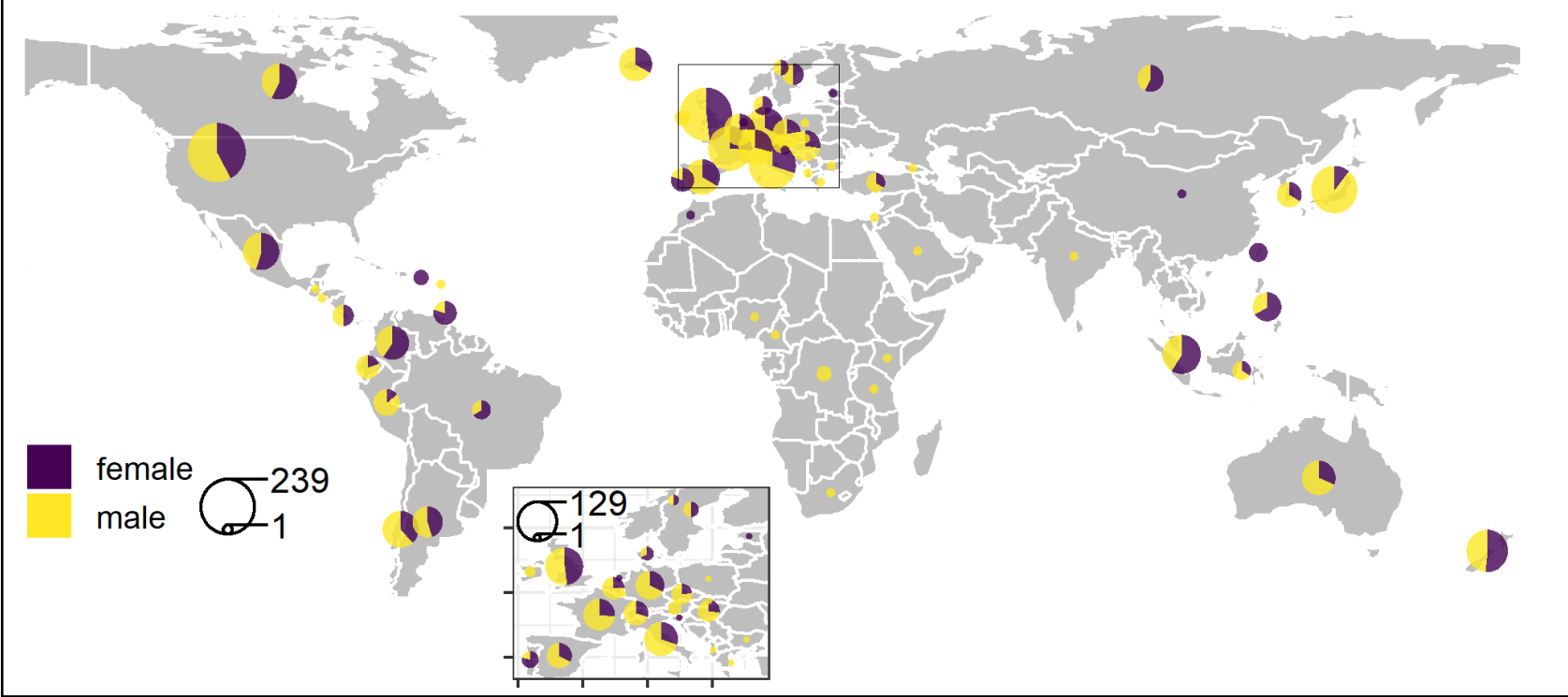

Figure 1: The number of IAVCEI members per country and percentage of female IAVCEI members in 2021. The inset map shows European countries in detail for clarity. 


\begin{tabular}{|c|c|c|c|c|c|c|c|c|}
\hline & Membership & Female $\%$ & Male $\%$ & Nonbinary & $\begin{array}{l}\text { Prefer self- } \\
\text { describe }\end{array}$ & Unknown & Other & $\begin{array}{c}\text { Prefer not } \\
\text { to say }\end{array}$ \\
\hline IAVCEI 2021 & 937 & $39.2 \%$ & $60.8 \%$ & $(-)$ & $(-)$ & $(-)$ & $(-)$ & $(-)$ \\
\hline AGU VGP 2020 & 2919 & $30.7 \%$ & $66.7 \%$ & $\begin{array}{c}3 \\
(0.1 \%)\end{array}$ & $\begin{array}{c}0 \\
(0.0 \%)\end{array}$ & $\begin{array}{c}42 \\
(1.4 \%)\end{array}$ & $(-)$ & $\begin{array}{c}29 \\
(1.0 \%)\end{array}$ \\
\hline $\begin{array}{l}\text { AGU VGP } 2020 \\
\text { ECR and Student }\end{array}$ & $1235(42 \%)$ & $45.8 \%$ & $52.2 \%$ & $\begin{array}{c}2 \\
(0.2 \%)\end{array}$ & $\begin{array}{c}0 \\
(0.0 \%)\end{array}$ & $\begin{array}{c}7 \\
(0.6 \%)\end{array}$ & $(-)$ & $\begin{array}{c}15 \\
(1.2 \%)\end{array}$ \\
\hline $\begin{array}{l}\text { AGU VGP } 2020 \\
\text { Non-ECR and } \\
\text { Non-Student }\end{array}$ & $1684(58 \%)$ & $19.7 \%$ & $77.4 \%$ & $\begin{array}{c}1 \\
(0.06 \%)\end{array}$ & $\begin{array}{c}0 \\
(0.0 \%)\end{array}$ & $\begin{array}{c}35 \\
(2.1 \%)\end{array}$ & $(-)$ & $\begin{array}{c}14 \\
(0.8 \%)\end{array}$ \\
\hline EGU GMPV 2021 & 1365 & $38.6 \%$ & $58.4 \%$ & $(-)$ & $(-)$ & $\begin{array}{c}14 \\
(1.0 \%)\end{array}$ & $\begin{array}{c}0 \\
(0 \%)\end{array}$ & $\begin{array}{c}27 \\
(2.0 \%)\end{array}$ \\
\hline $\begin{array}{l}\text { EGU GMPV } 2021 \\
\text { ECS }\end{array}$ & 808 (59\%) & $43.7 \% * *$ & $54.7 \% * *$ & $(-)$ & $(-)$ & $\begin{array}{c}6 \\
(0.7 \%)\end{array}$ & $\begin{array}{c}0 \\
(0 \%)\end{array}$ & $\begin{array}{c}27 \\
(2.0 \%)\end{array}$ \\
\hline $\begin{array}{l}\text { EGU GMPV } 2021 \\
\text { Non ECS }\end{array}$ & $557(41 \%)$ & $31.2 \%$ & $63.7 \%$ & $(-)$ & $(-)$ & $\begin{array}{c}8 \\
(1.0 \%)\end{array}$ & $\begin{array}{c}0 \\
(0 \%)\end{array}$ & $\begin{array}{c}27 \\
(2.0 \%)\end{array}$ \\
\hline
\end{tabular}

62 Table 1: Gender identity of members of volcanological groups in 2020/2021. Data for Early career researchers (ECR, including students) is also provided

63 in brackets where indicated: *AGU definition of Students plus Early Career Researchers, **EGU definition of Early Career Scientists, (-) indicates data

64 is not available. In all groups, there are a higher proportion of females in earlier career stages. 
The EGU GMPV report the gender, career stage and geographic location of members from 20162021. There were 1365 EGU GMPV members in 2021 across 69 countries (39\% female, 59\% male and 0\% Other gender, see Table 1, Figure S1a). Since 2019 EGU offers the option for members to select their gender as 'male', 'female', 'other' or 'prefer not to say'. In 2021, the top five member countries were Germany, the UK, Italy, France and the USA (Figure S2), and so the bulk statistics are strongly influenced by them. The global distribution and proportion of the EGU GMPV Early Career Scientists (ECS) members has broadly increased from 2016-2021 (Figure S3). Members joining from new countries, such as Pakistan, Nigeria, Bulgaria, or Georgia, tended to be ECS (Figure S2). During this time, there have been notable increases in the number of ECS members in e.g. Japan, the Netherlands, Ireland, Hungary, Canada, Spain, Portugal, and Italy, but decreases in Belgium and Sweden (Figure S3).

The AGU VGP reports the gender identity and geographical region of its members from 2013-2021 and their career stage up to 2020 . Since 2013 , these data have remained relatively stable, despite absolute numbers falling over this period (Figure S4). With 2919 members in 2020 (31\% female, $67 \%$ male and $0.1 \%$ non-binary), the AGU VGP includes more individuals than the IAVCEI 2021 or EGU GMPV 2021 datasets (Table 1). AGU offers the option for members to select their gender as 'male', 'female', 'non-binary', 'prefer to self-describe' or 'prefer not to say'.

The AGU VGP section has a lower percentage of students and Early Career Researchers (ECR) than the EGU GMPV ECS ( $42 \%$ compared to 59\%, Table 1), but these groups have a similar gender balance across the organisations. Both the AGU VGP and EGU GMPV data show that students and ECRs have a higher proportion of females ( $45.8 \%$ and $44 \%$, respectively) compared to the overall membership, and the AGU data suggests that this has been the case for several years (Table 1, Figure S5). The non-student, non-ECR, non-ECS groups have a lower female $(19.7 \%, 31.2 \%)$ and higher male (77.4\%, 
63.7\%) proportion than the AGU VGP and EGU GMPV bulk statistics, suggest a loss of women with advancing career stage.

There are limitations to these data. Whilst IAVCEI, AGU and EGU are the largest international groups that volcanology members can engage with, not all volcanologists are members. National volcanology-specific organisations or subject-specific sub-groups of IAVCEI, such as IAVCEI Commissions, also have their own members but generally do not collect demographic data.

The gender identity data currently available from IAVCEI is limited and is in urgent need of updating. Currently, IAVCEI members can only select 'female' or 'male' during registration, erasing non-binary and genderqueer scientists (e.g. Cameron and Stinson, 2019). It also does not allow for transgender scientists to identify as such if they wish. Individuals should always have the option to self-identify their gender in any demographics data collection (Strauss et al., 2021).

"no such data have ever [been] collected, practically as it was never really relevant to anything we've done." - an IAVCEI Commission Lead in response to our request for data

The lack of data means that the effectiveness of any actions put in place to improve EDI cannot be assessed. Recently some volcanology organisations and groups have started to collect membership data during registration to online events to learn about their members (e.g. an IAVCEI Commission on Volcanic and Igneous Plumbing Systems (VIPS) online seminar, and an IAVCEI Commission on the Chemistry on Volcanic Gases (CCVG) workshop). Other groups we contacted expressed a desire to understand better why such data collection is needed, how this should be done responsibly and how data should be stored.

\section{Who publishes in volcanology journals?}

The advancement of knowledge in volcanology is communicated primarily through scientific publications. Decisions about grant funding, postdoctoral appointments, and ultimately the ability 
to pursue an academic career is in part decided on an individual's publication record. To understand

112 who is allowed to create and disseminate knowledge we analysed data from two of the most 113 important volcanology journals (Stevenson, 2014) - the Journal of Volcanology and Geothermal 114 Research (JVGR, Elsevier) and the Bulletin of Volcanology (Bull Volc, Springer). The other 115 volcanology-themed journals we approached either did not respond or were unable to provide data. 116 We are not aware of any volcanology-specific journals that are not published in English.

117 The Bull Volc and JVGR data show a lack of diversity in lead-author affiliation country. The lead118 authors of volcanology articles are most often from Europe, North America, New Zealand and Japan 119 (Figure 2). Regions of the world with the most Holocene volcanic eruptions tend to have fewer or 120 no lead-authors published in JVGR or Bull Volc (Figure 2). Regions with under-represented lead121 author country affiliation and a higher rate of rejection (Figures S6 and S7), despite high volcanic 122 activity, include South America, Central America, East Africa and South-East Asia. This echoes similar 123 trends observed in broad geoscience publications (North et al., 2020) and may reflect a well124 established bias in academic publishing favouring the English-language (e.g. Ramírez-Castañeda, 125 2020) or a tendency for researchers from these countries to not lead volcanology articles.

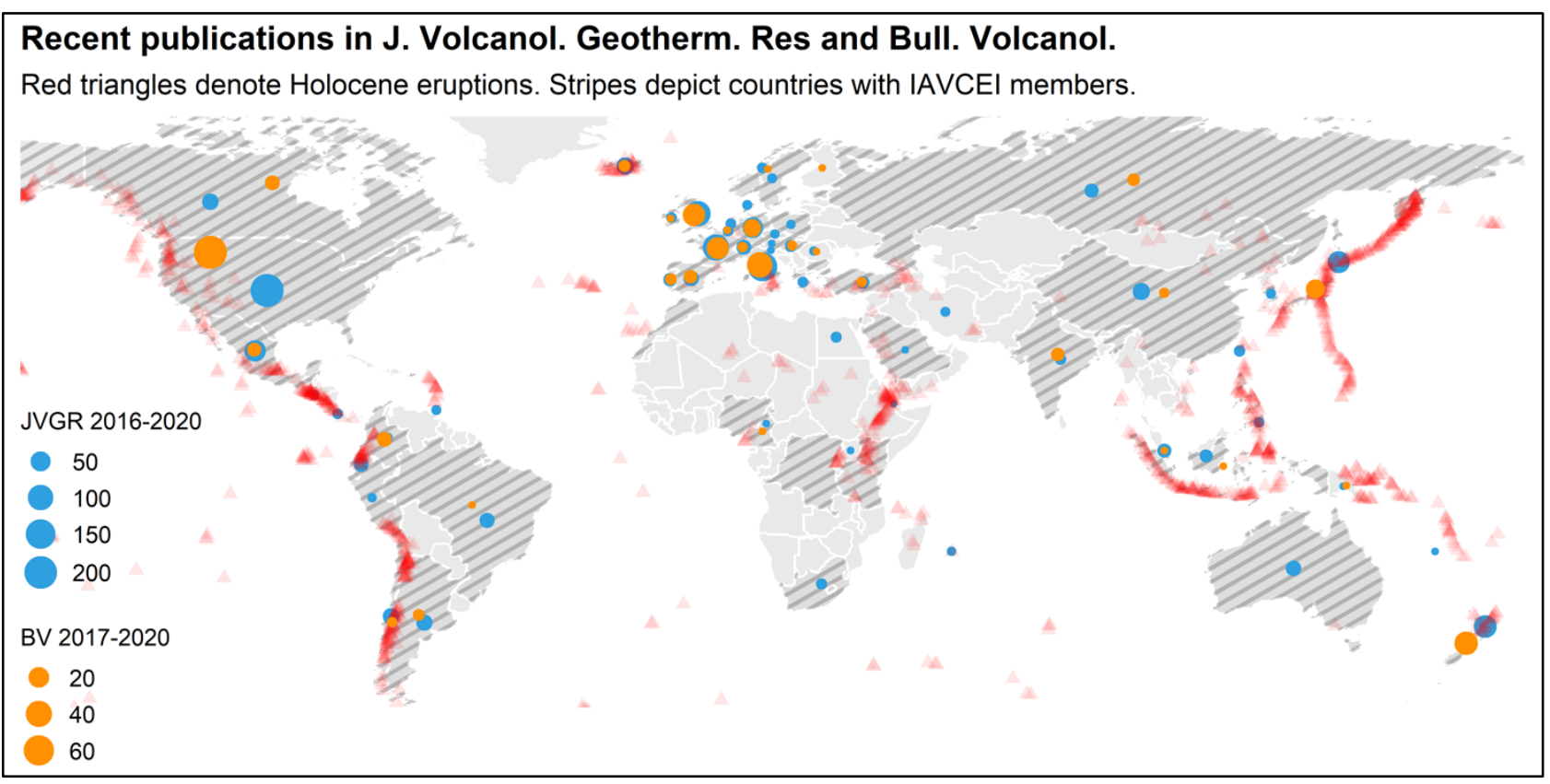


Figure 2: The total number and country of affiliation of lead-authors of articles accepted for publication in volcanology journals in recent years. The location of IAVCEI members and volcanic eruptions in the Holocene are shown for reference.

Our collated narratives reveal discrimination against some potential authors.

"Not being given the chance to co-author a paper despite having spent significant time helping out... I see others (both junior and senior folks) who contribute much less, sometimes hardly anything, repeatedly being put on papers, which only results in reinforcing their status as a wellknown and/or promising researcher. This practice tends to happen in the inner circle of the big volcano groups"

Publication authorship should be based on contribution, but in some research groups there is a perception that some contributions are 'valued' more than others:

"Women in volcanology are often 'forgotten' or their scientific contribution is devalued relative to a male of similar career stage"

A survey response suggests discrimination in publication authorship related to maternity leave:

"I have been erased by list of authors of papers I have written and I have worked for because I went on maternity leave"

Journals do not ask for information on protected characteristics of their authors or reviewers (and often not their editors) and so there is no data available to assess the contribution of different genders to volcanology articles. However, explicit or unconscious bias biases against the authors, the reviewers, or the editor may play a part in these decisions (e.g. Fox and Paine, 2019; Hagan et al., 2020; Helmer et al., 2017; Poulson-Ellestad et al., 2020). One editor wrote: "It seems clear that some authors and reviewers find it harder to respect my decision (or me?) than they would if I were a man." 
150 Publishers have a responsibility to act and address these issues (e.g. Mehta et al., 2020), but 151 pressure also needs to come from those who have a voice in the system to push for change (and 152 educate as to why it is needed).

\section{Who leads our community?}

"I feel that in volcanology there is a male-dominated culture, and this is reflected in many of the 'leaders' such as award-winners of leads of committees like IAVCEI are male. It's really hard to find diverse role models."

157 The gender identity of IAVCEI Committee membership since its inception in 1919 supports this 158 assertion. Women are under-represented in the IAVCEI Committee relative to their proportion in 159 the IAVCEI, AGU VGP and EGU GMPV membership. The current IAVCEI Committee comprises nine 160 (75\%) male and three (25\%) female members (see Figure 3A). Over more than 100 years, up to 161 today, $100 \%$ of the IAVCEI General Secretaries and $100 \%$ of IAVCEI Presidents have been men 162 (Figure 3A). IAVCEI is unique amongst the eight scientific Associations within IUGG in never having 163 had a woman or non-binary President. 

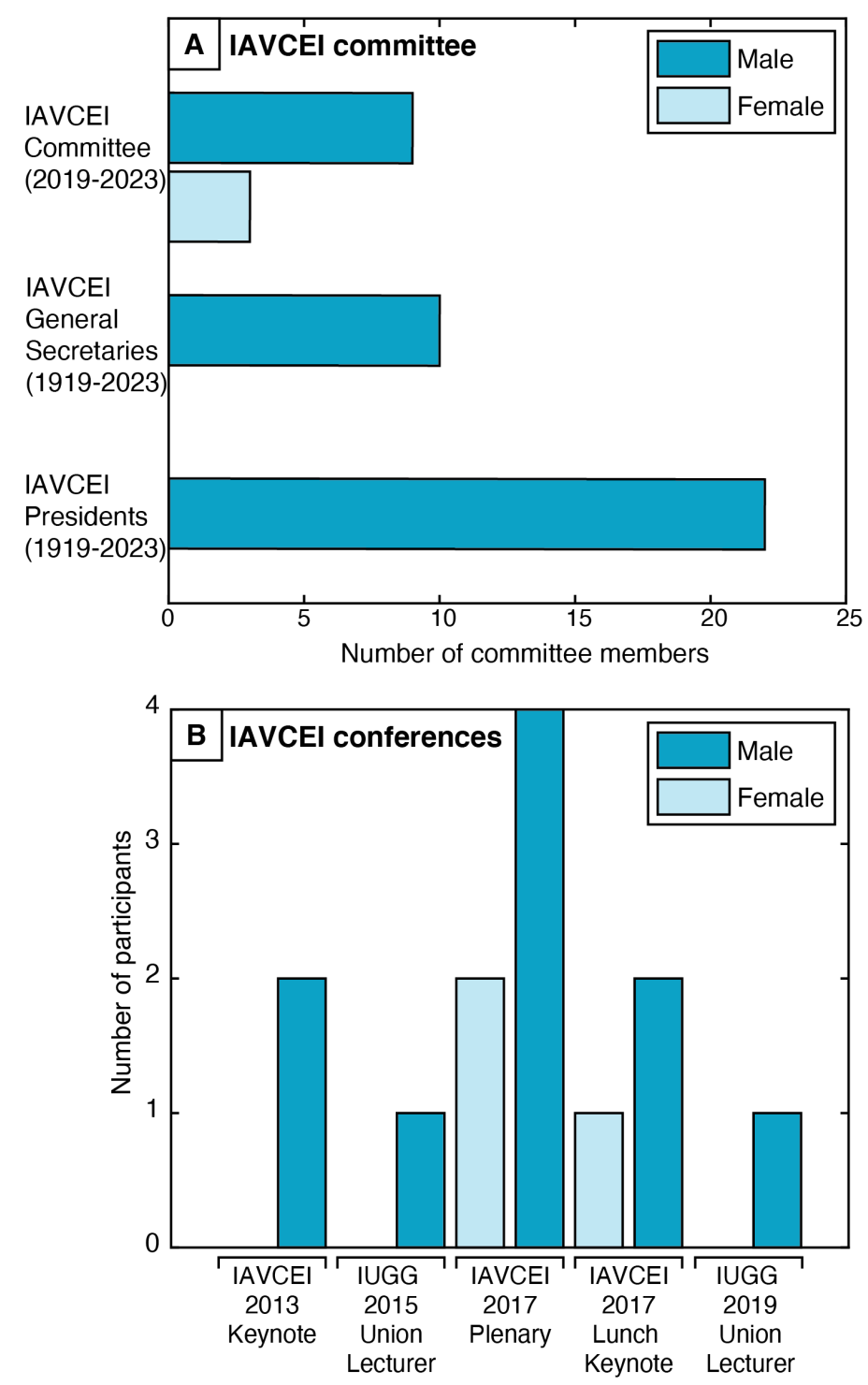

165 Figure 3: Gender identity of A) IAVCEI Committee leadership and members since 1919, and B) keynote speakers at IAVCEI General Assemblies, since 2013.

IAVCEI Commissions and Network board officers are slightly more diverse in gender than the IAVCEI

Committee, comprising overall $63 \%$ male and $37 \%$ female. This gender balance is not evenly distributed: Nine out of seventeen IAVCEI Commissions (mostly inter-associations ones) have a 100\% male board, five IAVCEI Commissions or Networks (including the ECR Network) have 50\% male

171 and $50 \%$ female board members, and one IAVCEI Commission has a $100 \%$ female board. Women

172 lead seven out of seventeen (40\%) of IAVCEI Commissions, two out of seven (29\%) inter-Association

173 Commissions and two out of two (100\%) of IAVCEI Networks. The newer or ECR-focused IAVCEI

174 Commissions or Networks, or those that have regular changes in their leadership, tend to have more 
gender equity or to be led by females, and this suggests gradual progress towards gender equity in the IAVCEI Commissions.

In the IAVCEI 2013 General Assembly, and the IUGG 2015 and 2019 conferences, Union Lecturers were 100\% male. At IAVCEI 2017 there were 33\% female Plenary and Lunch keynote speakers

(Figure 3B). The only instance of a woman giving a Plenary/Keynote was when there were a series of speakers. The issue of women and under-represented minorities giving fewer talks is recognised broadly across Earth Science conferences (Ford et al., 2019).

\section{Who do we reward?}

One way in which excellence in volcanology is recognised and celebrated is through awards and medals. Award winners are role models and are implicitly perceived as reflecting the values that volcanologists wish to promote.

The proportion of female award recipients decreases the more senior the medal in volcanology is (Figure 4). There are fewer women at the senior level in volcanology who would be eligible for these awards (e.g. Table 1), but the fact that we do not see women receiving senior awards sends a message to the younger generation that there is a narrow vision of what success looks like, and that the contributions of women and other underrepresented people are not valued. The IAVCEI Thorarinson medal for senior volcanologists has never had a female recipient. The awards that all career stages are eligible for have relatively low female recipients (e.g. $5 \%$ female recipients of the AGU Bowen Award since 1981) whereas the early career stage awards are much more balanced in gender (e.g. 50\% female recipients of the IAVCEI George Walker Award since 2004). The EGU award for students is unique in having a higher proportion of female recipients.

Recent trends show little improvement. Over the past ten years, the percentage of female awardees ranges from 0-61\% depending on the award category, and the more senior awards are associated 

are low relative to the likely proportion of non-ECR females in the volcanology community (Table 1), suggesting that senior women in academia win senior awards less frequently than their male counterparts. Over the past five years (2016 to 2021), in all cases there has been a small increase in

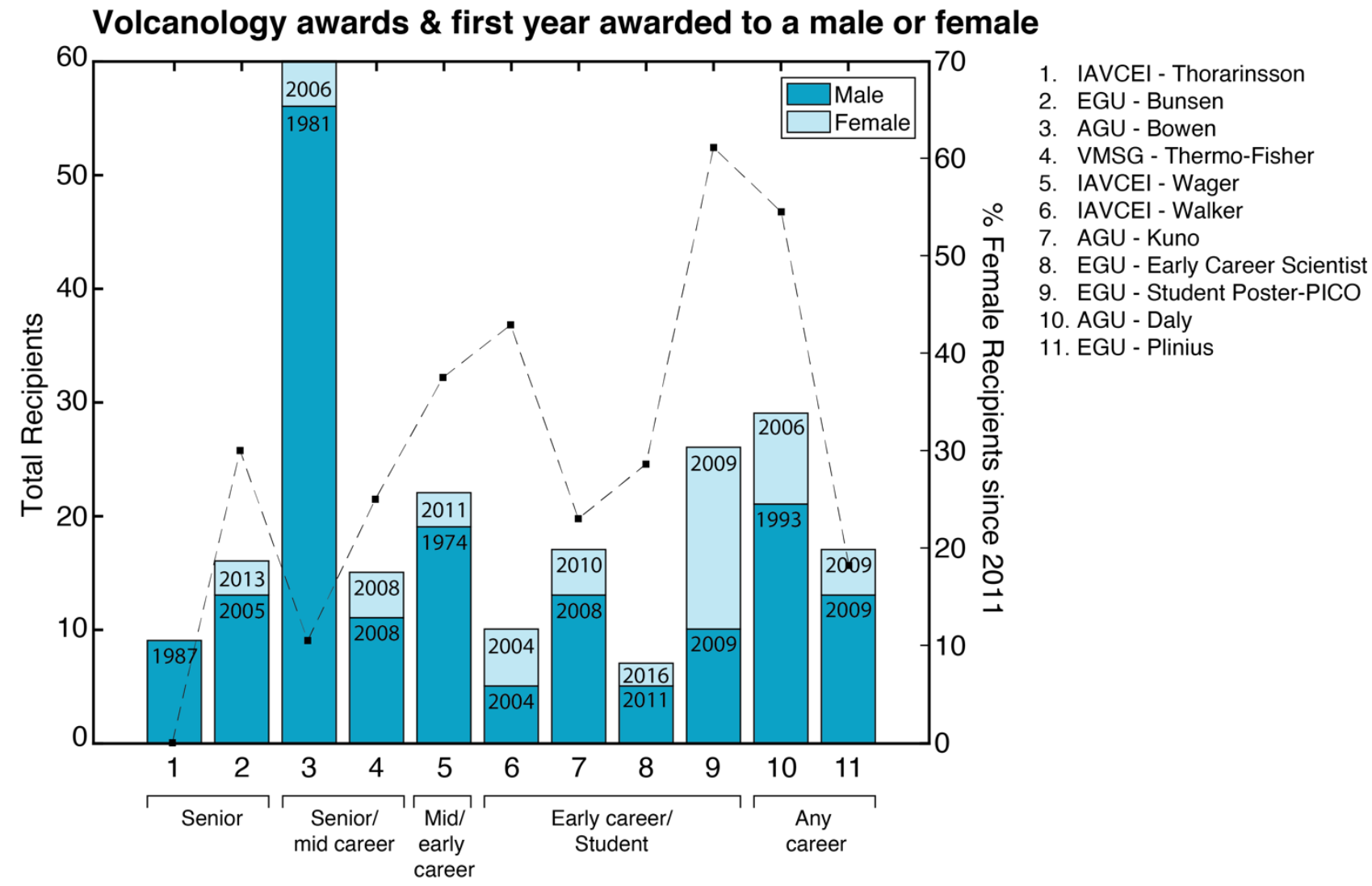

Figure 4: Gender identity of volcanology award winners for different career stages since the first year of data availability (bars), and the proportion of female recipients since 2011 (dashed line). The lower label on the bars indicates the first year of data availability and the upper label the first year there was a woman recipient. males were nominated far more frequently than females for their most-senior award, the Thermo-

Fisher Award, but when females were nominated they tended to be more successful (VMSG Website newsletter \#50 https://vmsg.org.uk/). Since 2010, there have been 79\% male and 21\% female VMSG 

appears that only outstanding females tend to be nominated for this award. Despite comparable quality of work, women are under-recognised by our awards, and men over-represented.

A common challenge for awards committees is ensuring nominations come in at all, and the selection committees can only choose from those who are nominated (McFadden, 2018). In a bold move which has helped to raise awareness, the AGU Cryosphere Section declined to recommend any nominees to the AGU Union Fellows committee in 2021 due to lack of diversity in the pool (Cryosphere Fellows Selection Committee, 2021). Perhaps other organisations also need to follow suit, or adopt an action plan (e.g. Ali et al., 2021), for what to do if/when a dramatically unbalanced nomination pool arises. The ambition must be that outstanding researchers will be nominated for awards, irrespective of their gender identity, status, socio-economic background, sexuality, ethnicity, etc., and yet the data we have accessed suggests that volcanology is far from realising 226 this.

\section{Experiences of discrimination in volcanology}

The lack of diversity in volcanology highlighted by our analysis reflects ingrained discriminations that affect the whole of society. The first step toward an inclusive, fair, more diverse, and therefore more creative volcanology community is the awareness and acknowledgement of the issues. We received over 100 responses to our survey, with some individuals providing free-text comments to describe instances of discrimination witnessed or experienced during their volcanology studies or work (see

233 Supplementary Materials). We have categorised these into 38 experiences and 17 witnessed 234 accounts of discrimination, with the most common reported forms of discrimination relating to 235 sexism (reported 30 times), activities during fieldwork (14 times), a toxic culture (9 times) and racism 236 (8 times) (see Figure 5). 


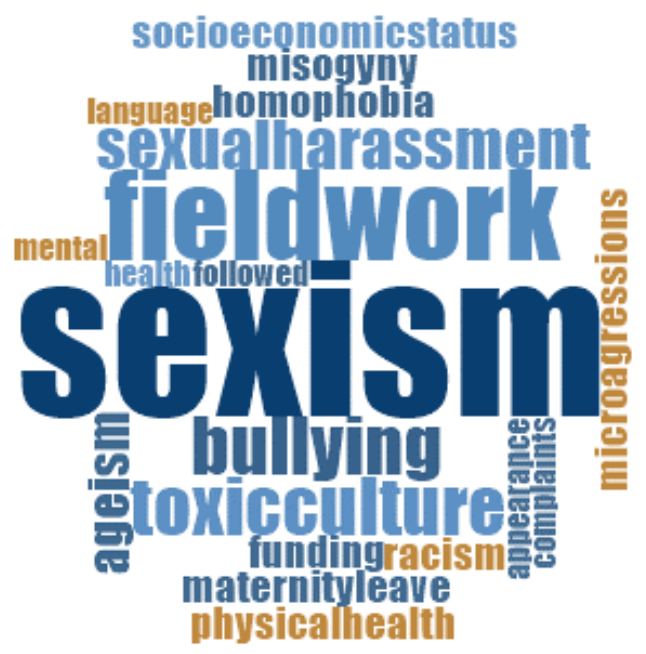

Figure 5: Word cloud of categories of volcanologists' experiences and witnessed accounts of discrimination in their work or study.

In an EDI debate at vEGU2021, it was stressed that responsibility for change should not be taken only by members of under-represented groups or those who have experienced discrimination; not only because these members are often not in a position of power, but mostly because the load of taking action should be fairly distributed. The impact of discriminatory experiences against, or 244 witnessed by, individuals can be profound, leading to mental health problems and victims 245 potentially leaving the field of volcanology. A fairer volcanology community is the responsibility of 246 all its members.

\section{Equality, Diversity, and Inclusion in volcanology: Looking forwards}

248 Our view of the future of volcanology is of a community that makes all its members feel welcomed and respected, and where all scientists can thrive. The rather sobering current state of EDI within

250 the volcanology community presented in this contribution should be a call to action for 251 organisations, scientific journals, and individuals. A number of works have recently constructed 252 evidenced action lists to address the lack of diversity in geoscience (e.g. Ali et al., 2021; Dowey et 253 al., 2021; Kaaden et al., 2021; Núñez et al., 2020). We conclude with recommendations to overcome 254 future EDI challenges. 
1. Awareness: Any change must be preceded by acknowledging the problem. Inequities in STEM research are well established in the literature. The data presented in this contribution proves these issues are also endemic in volcanology, however, our analysis has been hampered by a lack of quality data. We encourage organisations and journals to map out their specific state of EDI to become aware of their specific situation. This includes e.g. the collection of quantitative data on members, conference/event participants, authors, editors, and reviewers (using best practice for inclusive data collection), but also opening up for anonymous feedback from these people regarding EDI issues, or providing opportunities to discuss EDI. Several of the committees we contacted expressed a strong desire to be proactive in EDI, but felt uncomfortable collecting protected data from their members. We suggest that EDI-dedicated roles be created on the IAVCEI Committee who can oversee and advise on data collection so that the effectiveness of actions can be measured.

2. Commitment: Organisations and scientific journals should openly commit to EDI as core

3. Action: Organisations, journals, and conference organisers should aim for representation of 
unconscious bias and how to improve EDI should be a requirement for all members of organizational leaderships, grant review panels, prize juries, and conference organizing panels, but the effectiveness of these actions also needs to be monitored, and specific additional training should be available e.g. Bystander Training, Anti-racism training. Nomination procedures for distinctions and prizes should be made more inclusive by and conference organisers should provide visibility to diverse role models.

4. Reflection: Critical self-reflection and a willingness to address shortcomings should be part of everyone's development. There is clearly a lot of room for improvement if we all see our role in creating a better volcanology community.

\section{1}

\section{Acknowledgements}

We would like to thank the following individuals and organisations who provided or helped facilitate access to datasets: Patrick Allard (IAVCEI) and the IAVCEI Commission leads, Marian Holness (EGU), Dominique Weis and Billy Williams (AGU), Andrew Harris (Bulletin of Volcanology), Heidy Mader 295 (JVGR) and Sally Gibson (VMSG). JK thanks Graeme Lloyd and Andy Biggin for inspiring discussions 296 and Jenny Jones for editorial support. JK acknowledges a UKRI Future Leaders Fellowship 297 (MR/S035141/1). JM acknowledges an ERC Starting Grant (IMAGINE - 804162, PI Amy Donovan). 298 The use of survey data collected as part of this study is approved by a Research Ethics assessment 299 (\#2093) completed by Cambridge University’s Department of Geography Ethics Review Group. 
301 Funding: JK acknowledges a UKRI Future Leaders Fellowship (MR/S035141/1). JM acknowledges an 302 ERC Starting Grant (IMAGINE - 804162, PI Amy Donovan).

303 Conflict of Interest: The authors declare no conflict of interests.

304 Ethical approval: The use of survey data collected as part of this study is approved by a Research 305 Ethics assessment (\#2093) completed by Cambridge University’s Department of Geography Ethics 306 Review Group.

307 Informed consent: All survey participants provided data anonymously. 


\section{References}

Ali, H.N., Sheffield, S.L., Bauer, J.E., Caballero-Gill, R.P., Gasparini, N.M., Libarkin, J., Gonzales, K.K., Willenbring, J., Amir-Lin, E., Cisneros, J., Desai, D., Erwin, M., Gallant, E., Gomez, K.J., Keisling, B.A., Mahon, R., Marín-Spiotta, E., Welcome, L., Schneider, B., 2021. An actionable antiracism plan for geoscience organizations. Nat. Commun. 12, 1-6. https://doi.org/10.1038/s41467-021-23936-w

Bernard, R.E., Cooperdock, E.H.G., 2018. No progress on diversity in 40 years. Nat. Geosci. 11, 292-295. https://doi.org/10.1038/s41561-018-0116-6

Cameron, J.J., Stinson, D.A., 2019. Gender (mis)measurement: Guidelines for respecting gender diversity in psychological research. Soc. Personal. Psychol. Compass 13. https://doi.org/10.1111/spc3.12506

Cryosphere Fellows Selection Committee, 2021. Cryosphere Fellows Selection Committee [WWW Document]. Open Lett. to Cryosph. Sect. members “Cryo Fellows 2021.” URL https://docs.google.com/document/d/1zobCpWdjVFHNnCeyCWNreX8IfHx6zR_2x8PSnuqUhA/edit

Dowey, N., Barclay, J., Fernando, B., Giles, S., Houghton, J., Jackson, C., Khatwa, A., Lawrence, A., Mills, K., Newton, A., Rogers, S., Williams, R., 2021. A UK perspective on tackling the geoscience racial diversity crisis in the Global North. Nat. Geosci. 14, 256-259. https://doi.org/10.1038/s41561-021-00737-w

Dutt, K., 2020. Race and racism in the geosciences. Nat. Geosci. 13, 2-3. https://doi.org/10.1038/s41561-019-0519-z

Engwell, S., Gibson, S., Kavanagh, J., 2020. The Volcanic \& Magmatic Studies Group Equality, Diversity and Inclusion Report 2020. https://doi.org/https://doi.org/10.31223/osf.io/rgxh7 
Ford, H., Brick, C., Azmitia, M., Blaufuss, K., Dekens, P., 2019. Women from some minorities get too few talks. Nature 576, 1-4.

Fox, C.W., Paine, C.E.T., 2019. Gender differences in peer review outcomes and manuscript impact at six journals of ecology and evolution. Ecol. Evol. 9, 3599-3619. https://doi.org/10.1002/ece3.4993

Hagan, A.K., Topçuoğlu, B.D., Gregory, M.E., Barton, H.A., Schloss, P.D., 2020. Women are underrepresented and receive differential outcomes at asm journals: A six-year retrospective analysis. MBio 11, 1-21. https://doi.org/10.1128/mBio.01680-20

Helmer, M., Schottdorf, M., Neef, A., Battaglia, D., 2017. Gender bias in scholarly peer review. Elife 6, 1-18. https://doi.org/10.7554/eLife.21718

J. Anadu, H.A., Jackson, C.A.L., 2020. Ten Steps to Protect BIPOC Scholars in the Field. Eos (Washington. DC). 101. https://doi.org/doi.org/10.1029/2020EO150525

Kaaden, K. Vander, Ryan, C., Rivera-Valentín, E.G., Phillips, C.B., Haber, J., Filiberto, J., Denton, A., 2021. Creating Inclusive, Supportive, and Safe Environments in Planetary Science for Members of the LGBTQ+ Community. Bull. AAS 53. https://doi.org/10.3847/25c2cfeb.bf7d9e04

Lincoln, A.E., Pincus, S., Koster, J.B., Leboy, P.S., 2012. The Matilda Effect in science: Awards and prizes in the US, 1990s and 2000s. Soc. Stud. Sci. 42, 307-320. https://doi.org/10.1177/0306312711435830

Marin-Spiotta, E., T. Barnes, R., Asefaw Berhe, A., G. Hastings, M., Mattheis, A., Schneider, B., M. Williams, B., 2020. Hostile climates are barriers to diversifying the geosciences. Adv. Geosci. 53, 117-127. https://doi.org/10.5194/adgeo-53-117-2020 
and Prizes? [WWW Document]. From Prow. URL https://fromtheprow.agu.org/how-will-weaddress-the-lack-of-gender-diversity-in-agu-medals-awards-and-prizes/ (accessed 10.11.21).

Mehta, D., Bediako, Y., De Winde, C.M., Ebrahimi, H., Fernández-Chiappe, F., Ilangovan, V., Quezada, C.P., Riley, J.L., Saladi, S.M., Tay, A., Weissgerber, T., 2020. Research Communication: Ways to increase equity, diversity and inclusion. Elife 9, e60438. https://doi.org/10.7554/eLife.60438

North, M.A., Hastie, W.W., Hoyer, L., 2020. Out of Africa: The underrepresentation of African authors in high-impact geoscience literature. Earth-Science Rev. 208. https://doi.org/10.1016/j.earscirev.2020.103262

Núñez, A.M., Rivera, J., Hallmark, T., 2020. Applying an intersectionality lens to expand equity in the geosciences. J. Geosci. Educ. https://doi.org/10.1080/10899995.2019.1675131

Olcott, A.N., Downen, M.R., 2020. The challenges of fieldwork for LGBTQ+ geoscientists. Eos (Washington. DC). 101. https://doi.org/doi.org/10.1029/2020EO148200

Poulson-Ellestad, K., Hotaling, S., Falkenberg, L.J., Soranno, P., 2020. Illuminating a Black Box of the Peer Review System: Demographics, Experiences, and Career Benefits of Associate Editors. Limnol. Oceanogr. Bull. 29, 11-17. https://doi.org/10.1002/lob.10362

Ramírez-Castañeda, V., 2020. Disadvantages in preparing and publishing scientific papers caused by the dominance of the English language in science: The case of Colombian researchers in biological sciences. PLoS One. https://doi.org/10.1371/journal.pone.0238372

Stevenson, J.A., 2014. The most important journals in volcanology [WWW Document]. URL https://all-geo.org/volcan01010/2014/03/the-most-important-journals-in-volcanology/ (accessed 10.10.21).

Strauss, B., Borges, S.R., Faridani, T., Grier, J.A., Kiihne, A., Maier, E.R., Olsen, C., O'Neill, T., Rivera- 

the future of gender equity in planetary science. Bull. AAS 53. 


\section{Supplementary Materials}

\section{Supplementary Tables}

\begin{tabular}{|c|c|c|c|c|c|c|c|c|}
\hline Award & Career stage & Reporting period & $\begin{array}{l}\text { Frequency of } \\
\text { award }\end{array}$ & $\begin{array}{l}\text { \#Male } \\
\text { Recipients }\end{array}$ & $\begin{array}{l}\text { \#Female } \\
\text { Recipients }\end{array}$ & $\begin{array}{l}\text { First year } \\
\text { Female } \\
\text { recipient }\end{array}$ & $\begin{array}{l}\% \text { female } \\
\text { since } 2011\end{array}$ & $\begin{array}{l}\% \\
\text { female } \\
\text { since } \\
2016\end{array}$ \\
\hline $\begin{array}{l}\text { IAVCEI } \\
\text { Thorarinsson } \\
\text { Medal }\end{array}$ & Senior & $1987-2017$ & Every 4 years & 9 & 0 & $N / A$ & 0 & 0 \\
\hline $\begin{array}{l}\text { EGU (GMPV) - } \\
\text { Robert Wilhelm } \\
\text { Bunsen Medal }\end{array}$ & Senior & $2005-2021$ & Every year & 13 & 3 & 2013 & $30 \%$ & $33.3 \%$ \\
\hline $\begin{array}{l}\text { AGU - The Norman } \\
\text { L. Bowen Award }\end{array}$ & $\begin{array}{lr}\text { Mid- } \quad \text { or } \\
\text { senior career }\end{array}$ & $1981-2021$ & Every year & 56 & 4 & 2006 & $10.5 \%$ & $18.2 \%$ \\
\hline $\begin{array}{l}\text { VMSG - Thermo- } \\
\text { Fisher Award }\end{array}$ & $\begin{array}{lr}\text { Mid- } \quad \text { or } \\
\text { senior career }\end{array}$ & $2008-2021$ & Every year & 11 & 4 & 2008 & $25 \%$ & $33.3 \%$ \\
\hline $\begin{array}{l}\text { IAVCEI - Wager } \\
\text { Medal }\end{array}$ & $\begin{array}{l}\text { Early and } \\
\text { mid-career, } \\
\text { up to } 15 \\
\text { years post } \\
\text { PhD }\end{array}$ & $1974-2019$ & Every 2 years & 19 & 3 & 2011 & $37.5 \%$ & - \\
\hline $\begin{array}{l}\text { IAVCEI - George } \\
\text { Walker Award }\end{array}$ & $\begin{array}{l}\text { Early career, } \\
\text { up to } 7 \text { years } \\
\text { post PhD }\end{array}$ & $2004-2019$ & Every 2 years & 5 & 5 & 2004 & $42.9 \%$ & - \\
\hline
\end{tabular}




\begin{tabular}{|l|l|l|l|l|l|l|l|}
\hline $\begin{array}{l}\text { AGU - The Hisashi } \\
\text { Kuno Award }\end{array}$ & Early career & $2008-2021$ & Every year & 13 & 2010 & $23 \%$ \\
\hline $\begin{array}{l}\text { EGU (GMPV) - } \\
\text { Division } \\
\text { Outstanding Early } \\
\text { Career Scientist } \\
\text { Award career }\end{array}$ & $2011^{*}-2021$ & Every year & 5 & $25 \%$ & 2016 \\
\hline $\begin{array}{l}\text { EGU (GMPV) - } \\
\text { Outstanding } \\
\text { Student Poster and } \\
\text { PICO (OSPP) } \\
\text { Award }\end{array}$ & Early career & $2009-2019$ & Every year & 10 & $20 \%$ & 2009 \\
\hline $\begin{array}{l}\text { AGU - The Reginald } \\
\text { Daly Lecture }\end{array}$ & $\begin{array}{l}\text { All career } \\
\text { stages }\end{array}$ & $1993-2021$ & Every year & 21 & 16 & $61.1 \%$ & - \\
\hline $\begin{array}{l}\text { EGU (Natural } \\
\text { Hazards Division) - } \\
\text { Plinius Medal }\end{array}$ & $\begin{array}{l}\text { All career } \\
\text { stages } \\
\text { (2004-2011 } \\
\text { early career } \\
\text { scientists } \\
\text { only) }\end{array}$ & $2004-2021$ & Every year & 13 & 8 & 2006 \\
\hline
\end{tabular}

Supplementary Table S1: Volcanology awards for different career stages, and the first year that it was awarded to a female recipient. The percentage of female recipients since 2011 is provided, and since 2016 for awards given yearly up to 2021. *Award not given from 2012-2014. 


\section{EGU GMPV membership gender profiles}

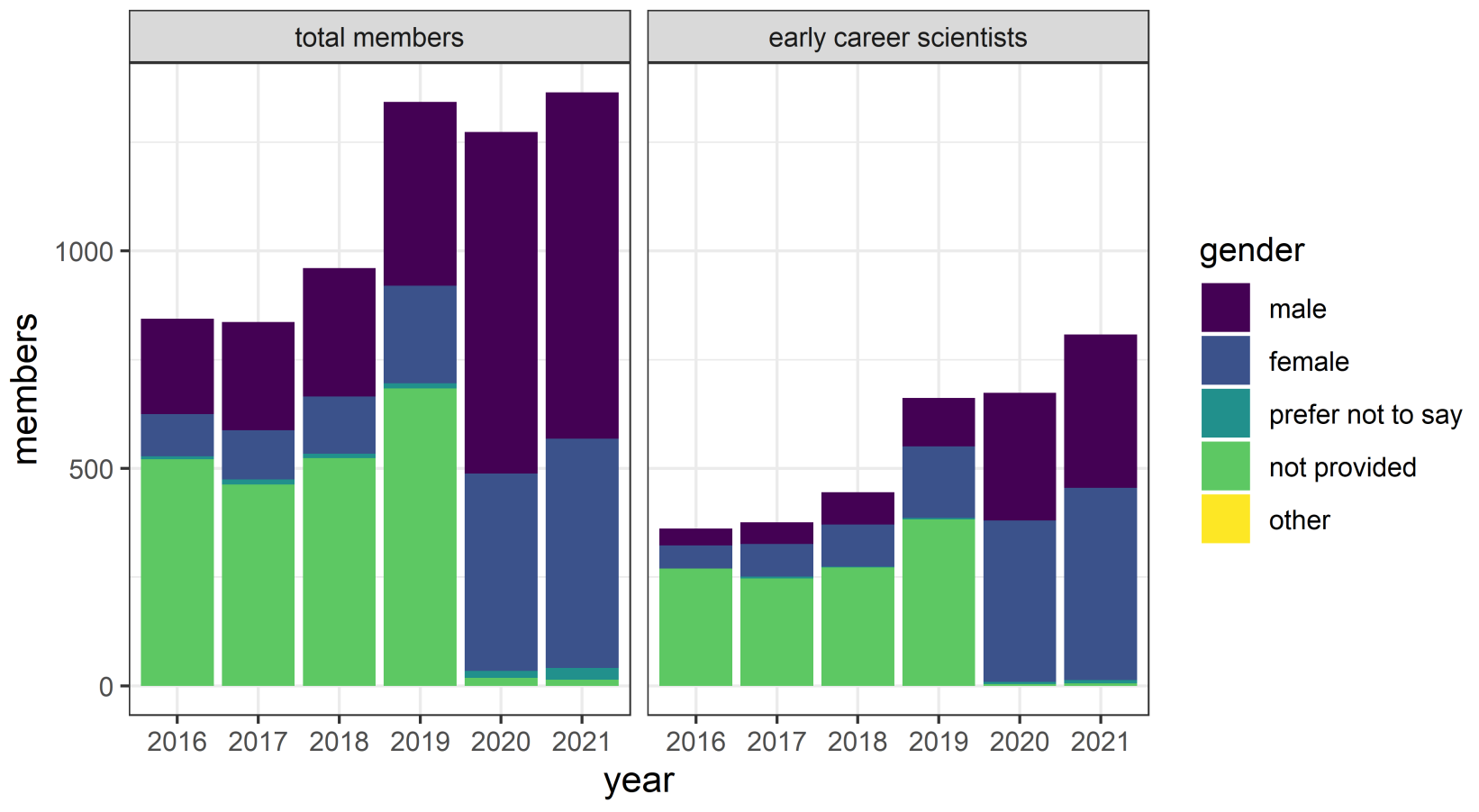

4 Figure S1: Gender identity of total number of EGU GMPV members and of Early Career Scientists 5 from 2016 to 2021. 


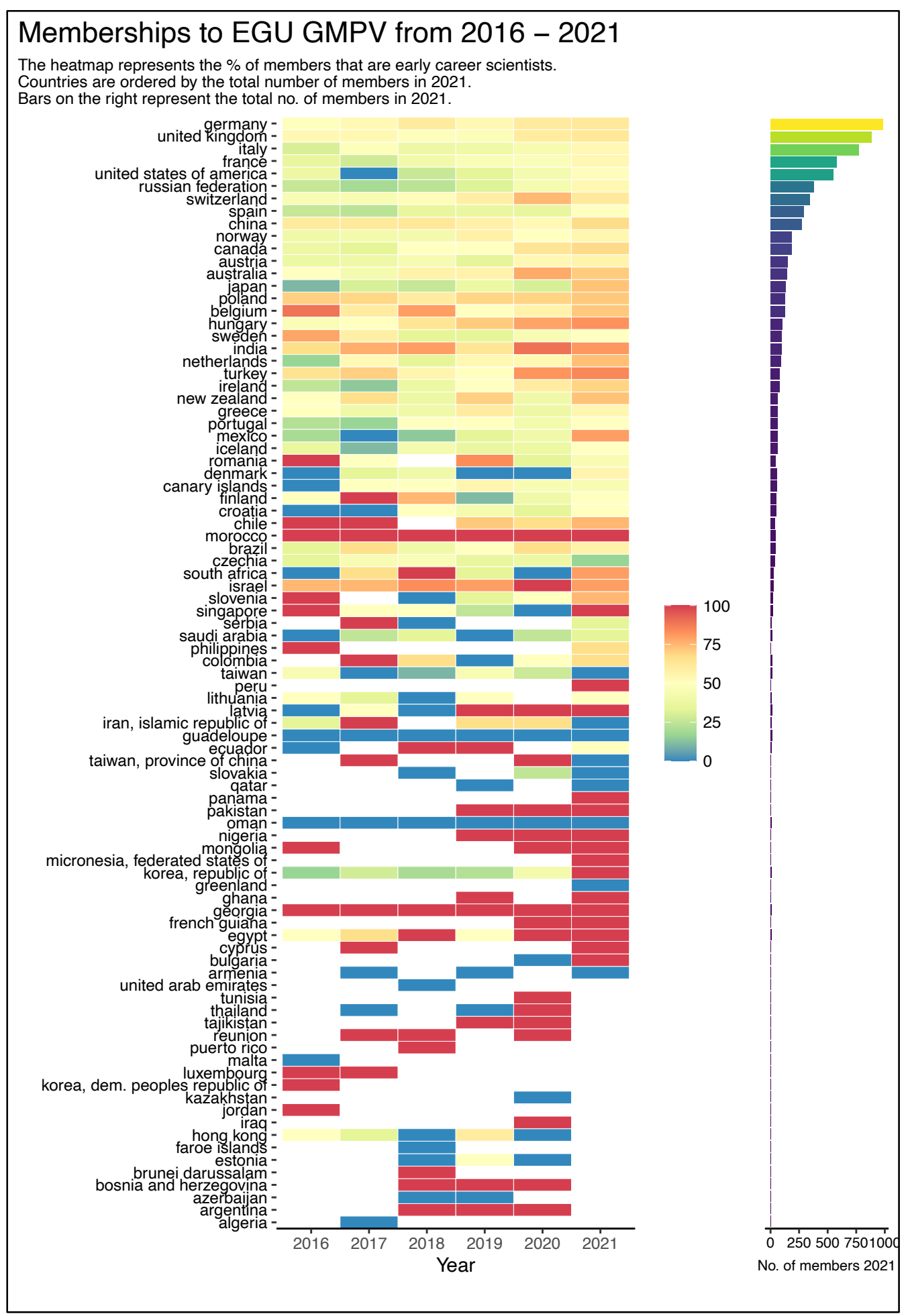

9 Figure S2: Total number and proportion of Early Career Scientists per country of EGU GMPV 10 members from 2016 to 2021. 


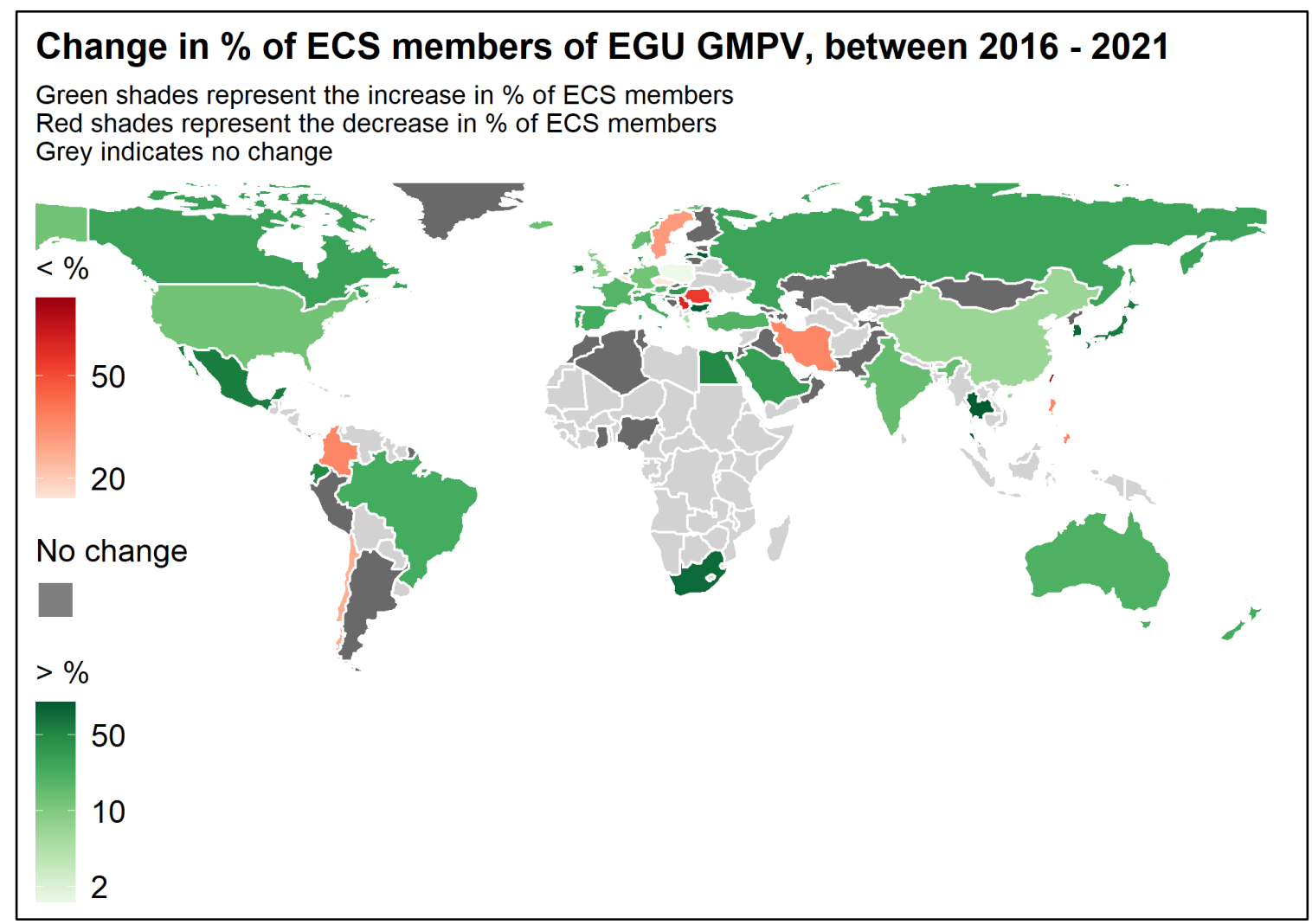

Figure S3: Change in \% of Early Career Scientists of EGU GMPV from 2016 to 2021.

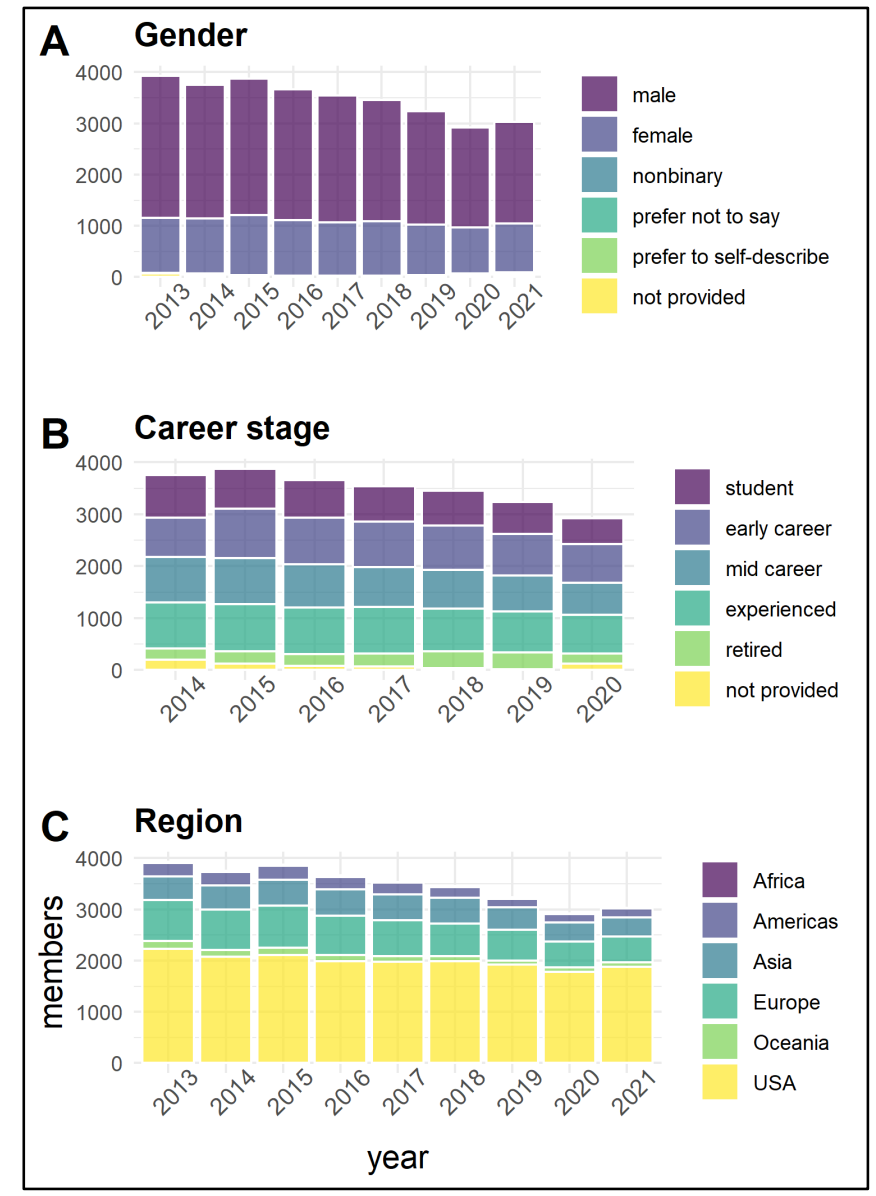

18 Figure S4: AGU VGP membership from 2013 to 2021: A) gender identity, B) Career Stage and C) Geographic Region. 


\section{AGU VGP membership gender profiles}

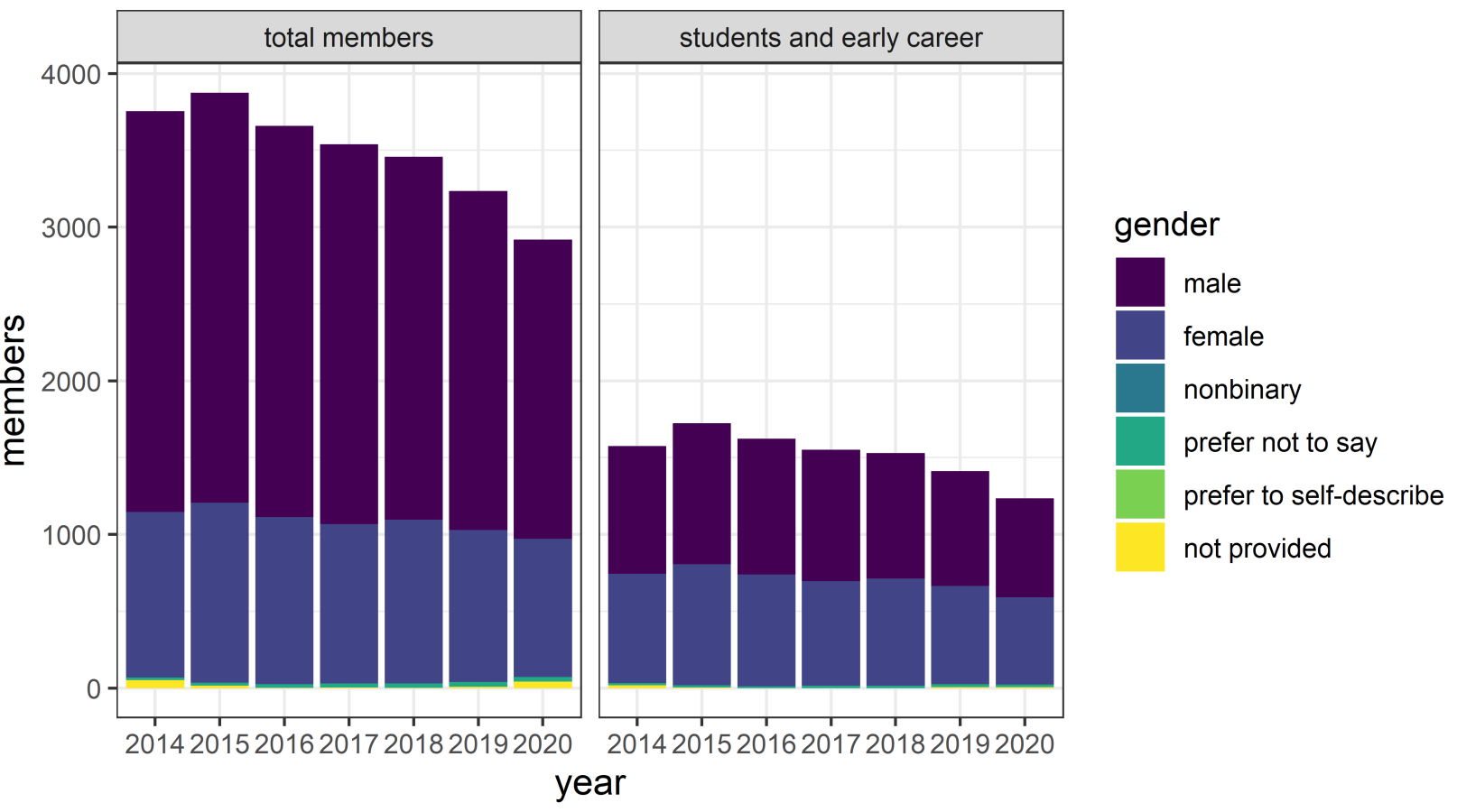

Figure S5: Gender identity of total number of AGU VGP members and of Students and Early Career

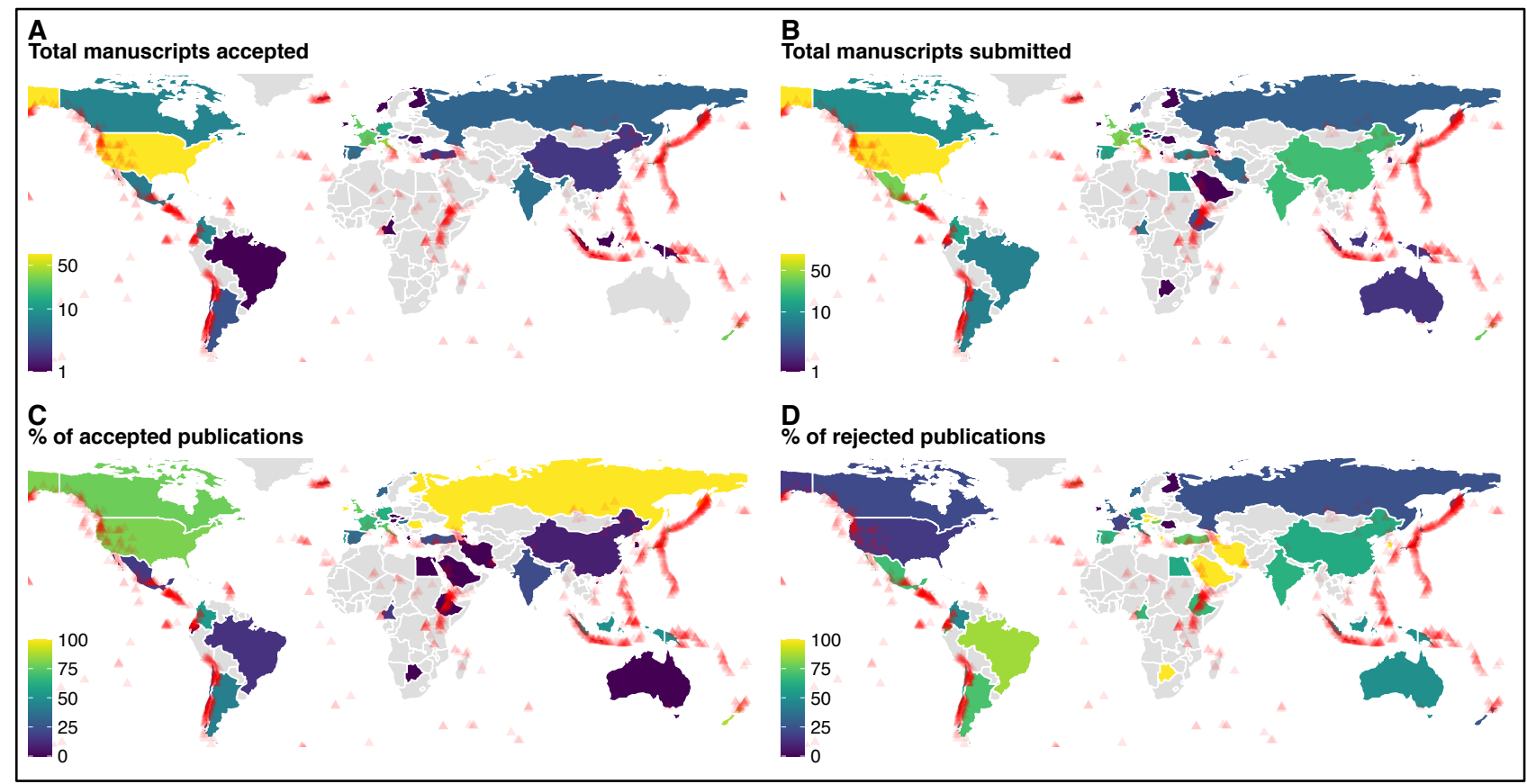

Figure S6: Bulletin of Volcanology publication statistics from 2017-2020: A) total manuscripts accepted, B) total manuscripts submitted, C) percent of accepted publications, and D) percent of rejected publications. 


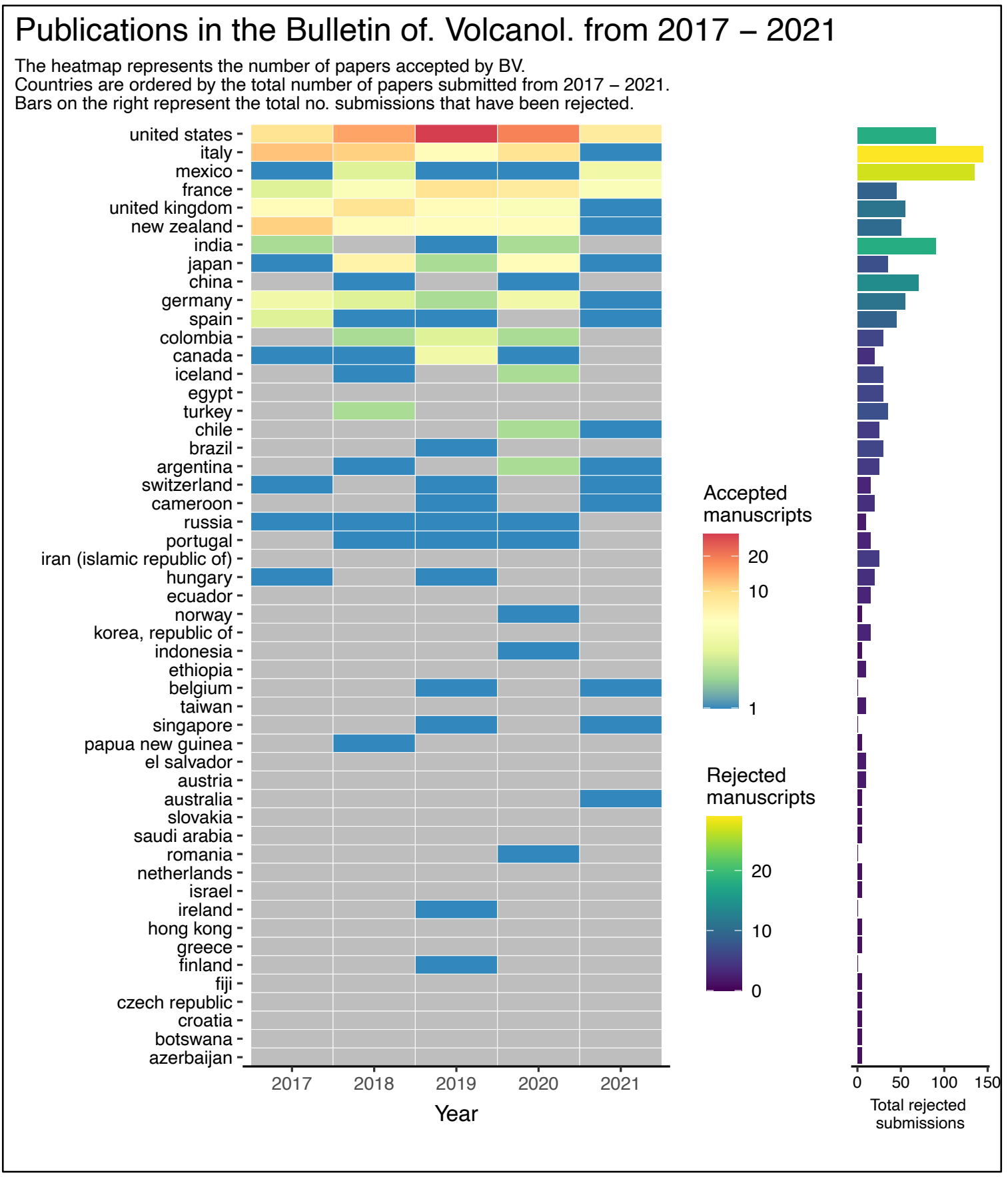

Figure S7: Heat map of the number of publications accepted and rejected by the Bulletin of Volcanology per country, from 2017 to 2020. 


\section{Description of Datasets}

Self-identifying, intersectional data collection is a powerful tool to understand demographic trends (Ali et al., 2021; Strauss et al., 2021). This section describes the datasets used in this paper.

\section{a. Volcanology Publications Data}

Bulletin of Volcanology - Data Source: Springer

- Number of submitted, accepted and rejected papers from 2017-2020

- Lead-author country of affiliation

Journal of Volcanology and Geothermal Research - Data Source: Elsevier

- Lead-author country of affiliation

\section{b. Gender identity datasets}

IAVCEI - Data Source: IAVCEI Secretariat/Guarant International

- Active members with dues paid by mid-2021

- Registration form includes: Gender (male/female), title, professional address

- Regular 1-year membership 50 EUR (lower for lower income)

- Young Researcher 1-year membership 15 EUR

\section{EGU GMPV - Data Source: EGU Executive Secretary}

- EGU membership GMPV division (2016-2021) as of $17^{\text {th }}$ May 2021

- Option to select up to 3 Divisions as main affiliations

- Registration form includes: Gender (male/female/Other/Prefer not to say), Career Stage, country of affiliation

- Gender identity data are less reliable back through time (<50\% gender reported before 2020) AGU VGP - Data Source: Business Data and Intelligence, Diversity Equity and Inclusion

- AGU membership VGP section (2013-2021) as of $24^{\text {th }}$ September 2021

- Registration data includes: Gender (Female, Male, Nonbinary, Prefer not to answer, Unknown, Prefer to self-describe), Career Stage (Student, Early Career, Mid-Career, Experienced, Retired, Unknown), Region of affiliation (Africa, Americas, Asia, Europe, Oceania, US, Unknown)

\section{c. Awards and Keynotes/Plenaries}

Aware of the caution expressed by Strauss et al. (2021) who demonstrated the harm that is done by inferring gender, we conducted internet searches to infer gender identity of the recipients of prizes administered by IAVCEI, AGU VGP, EGU GMPV and Natural Hazards Division, and VMSG (part of the Geological Society of London), based on publicly available lists of successful past recipients, to explore awards across a range of membership sizes and international/national groups. Where public information wasn't available we wrote to individuals to ask them how they would like their gender identity to be included in our analysis. Our approach was possible only because of the relatively small number of individuals who have received volcanology awards over the reporting period. Some awards have the option to award more than one recipient per year, and some awards do not make a reward every time if the nominations are not deemed appropriate (see Table S1 for details).

The names of IAVCEI Thorarinson, Wager and George Walker Award winners were obtained from the VMSG website. The names of AGU Volcanology, Geochemistry, and Petrology (VGP) Normal L. Bowen awardees, Hisashi Kuno awardees, and Reginald Daly Lecturers were obtained from the AGU 
website. The names of EGU GMPV Robert Wilhelm Bunsen Medal, EGU GMPV Division Outstanding Early Career Scientist Award, EGU GMPV Outstanding Student Poster and PICO (OSPP) Award and EGU Natural Hazards Division Plinius Medal were found on the EGU website. The names of the VMSG Thermo-Fisher Award winners were found on the VMSG website. The names of IAVCEI General Assembly and IUGG Union Lecturers since 2013 were obtained from the IAVCEI website.

The nomination process for most of these honours (excluding the EGU OSPP Award) relies on an external nomination letter and several additional letters of support. Because the language in support letters is rooted in an external assumption of gender and therefore the award is given within the context of those assumptions, we used the public perception of individuals to determine gender presentation. This included the public websites of individuals, press releases about the awardee receiving the award, pronouns in email and social media signatures, and other outward facing information.

We recognize that the outward perception of gender is not the same as an individual's self identified gender; for example, some non-binary individuals may choose to use only "safe" pronouns in professional settings or are comfortable using a variety of pronouns, some of which align with perception of a binary gender presentation.

\section{d. Committees and Networks and keynotes}

IAVCEI Committee structure - Data Source: IAVCEI Secretariat

IAVCEI Commissions and Networks - Data Source: IAVCEI Secretariat

\section{Survey on discrimination in volcanology}

Anonymous full transcripts from 116 responses, in random order, of free-text comments provided in response to the statement "Please share with us an occasion when you either witnessed or experienced discrimination in your work/study within volcanology. We will use these accounts to help raise awareness of the challenges certain individuals and groups face in volcanology - please be assured that all details will be anonymised." The survey was released $30^{\text {th }}$ September 2021 and the data are reported as of $13^{\text {th }}$ October 2021.

Any potentially identifying information has been removed in square brackets to maintain anonymity. Other than this, we have not edited these transcripts and have kept original typographic errors. The statements are numbered randomly and all respondents who wrote statements are included. Some of the statements contain phrases or words that are unacceptable. They reflect the view of the respondents only.

We have categorised these accounts as follows:

- Witnessed

- Experienced

- Toxic culture

- Bullying

- Narcissism

- Sexism

- Sexual harassment/Sexual assault

- Racism

- Homophobia 


\begin{tabular}{|c|c|}
\hline 119 & - Physical health \\
\hline 120 & - Mental health \\
\hline 121 & - Maternity leave \\
\hline 122 & - Language \\
\hline 123 & - Funding \\
\hline 124 & - Fieldwork \\
\hline 125 & - Socio-economic status \\
\hline 126 & - Public humiliation \\
\hline 127 & - Microaggression \\
\hline 128 & - Complaint \\
\hline 129 & - Other \\
\hline
\end{tabular}


\# Response

1 In my previous research group (where was one of the senior people), the PI regularly commented on other colleagues' nationality in a negative way. For example: "As is typical for [person from specific country] people, she's crude." "Professor $X$ is a refugee from [specific country]. Therefore he wants to build a new minority government here." Or "... Therefore he doesn't like women."

The PI also frequently discussed and actively tried to manipulate his PhD students private life. For example "PhD student Y's boyfriend is not good for her. He has far too much influence on her and distracts her from work."

Another example: The PI was seriously questioning another PhD student's commitment to her PhD when she started to date a new guy. The PI was inferring that the only thing she had on her mind was getting pregnant.

None of these things were openly mentioned to the people in question. Everything was discussed in the PI's inner circle of senior researchers. However, these discussions led to a lot of conflict in the research group and the department. The research group finally collapsed and the professor is now banned from supervising PhD students.

2 If I were to share my stories, I would have to write a book. Mabe I will eventually.

5 Derision from my advisor at the mention of wanting to start a family. Overt racism to a [specific country of origin] colleague for "having bad English" - she's a US citizen and speaks English at a native level.

6 1) When I was a MSc student, I was publicly humiliated for wanting to do a PhD with a well-known researcher in volcanology by a member of my own research group. This person had a history of being narcissistic and demeaning bully, and at the time was not progressing in his project. I was also one of a few students in the department who comes from an ethnic minority and was successful in my project, and the bully was Caucasian male student. It took years to disclose this incident to my ex-supervisor, and impacted my PhD experience extremely negatively. When I did disclose it to said ex-supervisor, instead of supporting me, he blamed me for not speaking up and never even bothered to name the perpetrator in his assessment. The ex-supervisor continued to show support for the bully. Members of the public who were at the incident also did not intervene, and one of them claimed they "didn't know" how to respond.

2) I also strongly believe I was discriminated against based on my race in a wellestablished funding competition, where the same bully in (1) won [a certain number of times] without having shown progress nor fulfilled $2 / 3$ of the stipulations listed in the eligibility section. One of the stipulation stated that the applicants should present their research at an in-house symposium, but he did not [do this]. The panel was [not diverse], and the winners heavily reflected favouritism for their students.

3) in the first few months of my PhD I encountered quite a few instances of hostile gatekeeping behaviour from two well-known "popular" postdoctoral researchers. 
They bluntly said that "there were too many PhD students" during my first few months as a PhD student, and heavily implied that I won't get a faculty job before I had a chance to prove myself. They had issues landing jobs, and likely saw me as an opportunity to vent their frustrations.

I was propositioned by a male student in front of a dozen other male students and two male profs, on a field trip. No one did or said anything.

On a field trip, in the desert, it was hot and we had all been drinking a lot of water, so everyone really needed to urinate. On a pause, every other participant (all male) simply turned their backs on the vans and peed. Since there was no cover, I could not pee in privacy so had to wait. I asked the trip leader to stop at a gas station so I could use the toilet, but he refused because he said he was in a hurry. I had to wait several hours, badly needing to urinate, before I was finally allowed access to a toilet.

In university, I witnessed a prof make disparaging remarks about a [person from a specific country] classmate. The same prof was also sometimes both misognyistic and racist at the same time: on a field mapping exercise in a small town, he said "There will be no all-girl mapping teams, because you need men to protect you from the drunken Indians".

At my current job, on a field project, a supervisor told two male summer students that my mineral identifications were wrong and suggested I was incompetent (he never spoke with me about any supposed errors in my work). He also gave me instructions, which I followed, then publicly chastised me for following the instructions. This same supervisor ignored several female summer students who did not meet societal standards of prettiness, providing no assistance with their projects and barely even speaking to them, while lavishing aid and attention on several conventionally pretty students. His attentiveness did not correlate with the actual academic skills, work effort, and overall performance of any of the students.

At my current job: when I returned from maternity leave, a senior manager (male), asked me if I was going to get pregnant again, and asked if he should have a talk with my husband to ensure I did not. This same manager has harassed and belittled me for over a decade - this is not obviously "sexual harassment", but he treats most if not all female colleagues this way and has a string of formal complaints against him that does not appear to have affected his career in any way.

I note that although none of these examples of harassment appears particularly horrific (I was never physically threatened or touched), many of them either don't fit a formal definition of harassment and/or are impossible to prove, and several are not obviously linked to sex, they all fit into a longstanding pattern of low-level harassment: questioning the competence of women, treating women like sex objects, denying the needs of females while giving male students/workers whatever they need. If someone threatens you at work, you can make a harassment complaint. However, when you are just treated a little differently, a little worse, over and over again, you have no recourse and just have to endure it. 
Dealing with a single episode like those I have experienced would not be a big deal. However, dealing with a career-long string of incidents like these, involving multiple male colleagues in different organizations, has severely impacted my self-confidence, and made it really tough to assert myself in work situations.

I add that the instances of racism and homophobia I have witnessed, although not directed at me because I am white and hetero, were really disturbing, and I am sure they are just the tip of an iceberg. I can only imagine how hurtful and anger-inducing such events (no doubt also part of a prolonged pattern) are for the victims.

9 Witnessing gender/Physical discrim: have witnessed a male senior volcanology professor say openly and scathingly that someone was no good for a PhD project because "she was too fat to get up the hills"

Subject to inappropriate behaviour by senior male volcanologist on trip: I was on fieldwork as a junior PhD student with senior male academics where one male professor told me that another male senior volcanology lecturer (married) quote "likes me" and I should "watch out for him, he's bad news". As an early career PhD, I felt incredibly uncomfortable during the whole trip because of the senior lecturer's inappropriate flirting, and felt ashamed that others on the trip may think I was encouraging it.

Subject to gender discrimination by another woman: I have been at a conference social as a PhD student where I played pool with a volcanology professor-nothing untoward, platonic. Afterwards, a female volcanologist told me "x likes blondes" suggestively, and insinuated I was trying to flirt with him to get ahead. For a long time this has stayed with me, as it was from a fellow woman. It made me feel I would never be taken seriously.

These incidents, unfortunately all during my $\mathrm{PhD}$, made me see volcanology as a very toxic place for a woman.

11 I was assaulted on a field trip ran by [specific Geoscience organisation], by another person attending the field trip. They tried to pull to their room to sleep with them and wouldn't listen when I told them no.

I got told to smile more and be more attractive on feedback from [specific student presentation assessment] at [specific international conference].

A well known volcanologist took an interest in my work and asked me to come on field work with him from very early on. As soon as other people left us alone on the trip, he asked me to come to his room and started undressing in front of me. He also got drunk and drove us back to the hotel whilst drunk. I had no other way to get back otherwise I wouldn't have gone with him. He constantly told me that my supervisor didn't get me and that I should only talk to him. He also told me to stop acting like a victim when I answered a question he asked me about previous negative experiences I had. 
A lot of jokes about how I speak, saying how 'common' it is. Telling me I would have to sleep with my supervisor to get my PhD.

14 I have experienced and observed discrimination against individuals with autistic spectrum disorder (ASD). I believe, in my own experience, that this form of discrimination and a general lack of understanding surrounding this complex condition is more common than many would believe, and it is sadly regarding as being of less interest when compared with discrimination based on other characteristics such as gender or ethnicity.

My own experiences of this style of discrimination range from a benign disregard or slightly cruel amusement at efforts made by someone such as myself to appear 'normal' and blend in, through to a quite intense and targeted campaign of workplace bullying, which prompted severe depression and self harm. On one occasion, facing regular verbal intimidation from a more senior staff member, I was so distressed by the prospect of going to work and unable to function adequately that I took a shard of broken glass to my own neck. The individual in question was the departmental equality and diversity officer, and knew that she could treat me as she wished without fear of punishment based on the fact that I was, due to my ASD, not socially capable of handling her regular verbal attacks or managing the intimidating and confrontational situations she forced upon me. This included e-mail barrages, regular insinuation of inadequacy in my job and general failure to provide required support, face-to-face bullying, and threats of false accusations of sexist behaviour.

No action was ever taken against the individual, and she is still working in the same institution, having been promoted to a more senior role as recognition for her contributions to equality and inclusivity in the workplace.

15 I have been erased by list of authors of papers I have written and I have worked for because I went on maternity leave

16 I feel that in volcanology there is a male-dominated culture, and this is reflected in many of the 'leaders' such as award-winners of leads of committees like IAVCEI are male. It's really hard to find diverse role models.

When I was a PhD student (10 years ago now) there were a few male volcanologists who seemed to use social activities as an opportunity to try and seduce female PhD students. I really hate that so many of the social activities in volcanology seem to revolve around alcohol. I hope things are changing, but I'm really not sure they are.

I think that women in volcanology are often 'forgotten' or their scientific contribution is devalued relative to a male of similar career stage. For example, in my previous institution there was an example of a male and female PhD student working together on a project - the male was automatically put by the supervisor as a co-author on the female's paper, but the female in the end was not a co-author on the male's paper yet their scientific contribution were the same.

It is so infuriating to see editorial boards of books, or IAVCEI Commissions for example being all male. The impression is that there are no female leaders in these fields, but 
when you see contributions at conferences this clearly is not the case. Are women not being invited? Or are they not accepting the invitations?

At my current work place I see every day evidence that I am treated differently by support staff, and sometimes my colleagues, because I am a woman. I feel I am expected to do more 'low skill' and time consuming tasks compared to my male equivalents. I am asked also to do more administrative tasks than my male colleagues, and I'm supposed to feel it is a compliment to be asked as they know I will do a good job. Yet these tasks take time away from my scientific research, which is ultimately on what my career progression is based. I really wish I had a mentor to guide me in my career and more positive role models.

I feel like organisations such as IAVCEI really need to step up, recognise there are real issues in volcanology that need to be addressed related to gender, ethnicity and other important factors, and show real leadership in bringing forth positive change in our subject.

18 I was repeatedly asked to leave talks at [specific international] conference[s] for standing at the back (I have to stand because of my chronic illness). I had asked in advance If this was okay and had been told it would be fine, but every single talk I attended security questioned me, in some cases let me stay but it was still very disruptive, in others told me I had to leave, no exceptions to no standing rule.

21 joking' casual homophobic remarks were common at this [specific country] University in lecturer offices in the 2010s, and it was hard to listen to if you weren't out then like me. It makes it worse in the present day that some people who did this now have very senior positions in the scientific community and virtue signal all the time on social media about equality and social justice. Literally the definition of not having integrity. I'm not sure they even realise they did this in the past.

22 Assumptions about sleeping arrangements on field work without checking re sexual orientation

23 was fondued by female boss

24 Passed over for student fieldwork opportunities (even though I am very qualified) because I am not regarded as "outdoorsy" due to gender, race and other social factors.

26 During a field experience, the field leader was very strict about not allowing women to fall behind the group while we were walking to the next location to go to the bathroom. There were no trees in the area so the best option for going to the bathroom and avoid being discovered was to go when the group was moving together in one direction when we passed a large-enough rock. Once the women re-joined the group, we (all members together) were loudly reprimanded, including degrading our work ability and cursing at us.

"Early career" fellowships, grants, and poaitions have age cutoffs. This runs counter to the Braided Stream model of career progression. I have "aged out" of many such fellowships and positions. 
28 I have personally received comments about my appearance as a woman at conferences mainly things like how it is "so much easier" to pay attention to a "woman in a dress" giving a scientific presentation. I have also gotten negative comments about my age or disability. I am fortunate that my experiences have stopped at just comments (that I know of).

I don't know if it counts for your survey, but I have heard (not witnessed) first hand instances of sexual harassment and manipulation (abuse of power) of students, undergrad to $P h D$, and post-docs, and even senior faculty. Everything from professors sleeping with students and postdocs, to withholding funding from students if they didn't dress a certain way when asking for the money for a chemical or equipment they need for their research, to taking photos up female undergraduate/Honours/MSc's skirts and ranking students based on their attractiveness on field trips. In my experience, all of these complaints were against 2-3 professors only, but their actions and comments affect the morale and well-being of the entire department substantially.

31 Not being given the chance to co-author a paper despite having spent significant time helping out. At the same time, I see others (both junior and senior folks) who contribute much less, sometimes hardly anything, repeatedly being put on papers, which only results in reinforcing their status as a well-known and/or promising researcher. This practice tends to happen in the inner circle of the big volcano groups at the "renowned" [specific country] universities (who tend to belong to the same academic dynasty); though it might of course be more widespread. If you enter the space as an outsider (foreigner, with a degree from elsewhere) you just have this feeling you will never really belong, no matter how friendly people are to you in your face.

33 Crying white female coworkers are bullying entire divisions, males, females, handicapped, colored people alike, and draw all attention by superior onto them.

35 Colleague got pregnant during her PhD, didn't get her contract renewed, had to move department to finish her thesis. Male colleagues with children get renewed contracts all the time, even get permanent positions offered.

In the field I'm always careful to express discomfort, cause otherwise I get the pity look and the frown of "women, weak" from my almost all male group of collaborators. If I'm talking about packing for field and considerations on garments and what to pack I'm often reminded that I'm not going for a catwalk. Of course it's just a joke, never addressed to male colleagues tho...

37 My previous boss, didn't hear my suggestions or ideas, he only agreed if one of my male counterparts mention the same thing. / I know of female colleagues that were paid less than the male counterparts for the same job, and same boss./ Due to my accent while doing my grad students some people dismiss me because they didn't understand me, instead of letting me explain. / During a field campaign I notice how a fellow PhD student was treated as a "personal assistant" to her PhD advisor. On the field, she carried everything, marked everything and in the camp site, she was in charge of food and everything else as well.

38 I experience gender based discrimination regularly during fieldwork season. Usually related to $4 \times 4$ driving, being in remote terrain without men etc. I am a qualified wilderness EMT and have $8+$ years of $4 x 4$ winter and summer experience in difficult terrain. I am purposefully seeking out extra qualifications (medical, mountaineering or 
driving based) just so I can be given the same opportunities as men in my field with less experience.

39 Staff members in my department have made very negative comments about LGBT people, presumably under the assumption that no one listening is part of that group (I am, but closeted).

45 - repeatedly being asked if I got my job because I was a woman in post-doc position - commonly asked to perform extra admin duties, while equivalent males given extra time to do research

- male colleagues present my ideas, research, results, work as their own

48 Jobs and funding going to females that are less qualified than male counterparts. Jobs going to known people in own network

51 I was the only female and only westerner in my research group ([list of students from particular countries]). I was called fat and weak repeatedly and basically abandoned for the last two years of my PhD. When I asked if students from the [other specific continents] were just not applying to my advisor he said, no they do, I just find that they aren't as good as [person from a particular country] at math so I don't accept them. I did enjoy the perk of having my own office with a window because it was inappropriate for me to be in the same workplace as men, but it left me very isolated scientifically and socially.

52 A senior male volcanologist, without consulting me, made decision that because I am a woman (his words) I should not be deployed for field work that involved sleeping in dusty and primitive conditions. I would have LOVED this opportunity, and had no concerns about the dusty and primitive conditions.

Less than half an hour after it was announced at the end of a major conference where the following would be held, at a place near where I live, I congratulated one of the coorganizers, a white senior male I didn't know that well but had interacted with in the past. His immediate response was, do you want to be on the organizing committee, we need a woman. There was no mention of why me (I provide access to x community, I am knowledgeable in y discipline, etc.), only my gender was of interest.

The [specific conference] cultural performance celebrating the end of the conference sexualized and objectified teenage women. That was very upsetting, and put a damper on the conference for me.

The [specific conference] plenary speakers were all male the first four days of the five day conference.

54 Verbal sexual discrimination from elder male volcanologist to younger female volcanologists is rather prolific. I've witnessed this both verbally and physically numerous times. From professors inappropriately stroking their students backs, hair, arms, etc. to being smacked on the ass or told, "I wish I was more than your professor." These instances are honestly too numerous to remember. 
55 At my previous position, research scientists (particularly male) treated lower payscale support staff (GIS, web, technicians) like crap. They ignored them, excluded them, teased them, and discredited them. It was awful.

56 Several times me and my female colleagues were declined to go to field trips based solely on our gender (female)

60 I'm a white male, so subject to very little discrimination. But when I was being considered for promotion at one time, I had multiple colleagues tell me that I was young, and still had plenty of time to advance, and that it was a bit "early" for me to be promoted. My age (below 40 at the time) should not have mattered -- just my record. Obviously a very minor episode compared to what others have experienced.

62 Discrimination may be too strong but it is perceived to be there owing to widespread 'casual sexism'. Comments and instruction on how to dress, limited physical capabilities, inappropriate behaviour from senior male collaborators. Pay gap in expenses handling.

63 Many years ago, I applied for graduate school and was accepted to work with a prominent, male volcanologist. Unfortunately my sir name is a male first name, and the advisor assumed I was male.

On arriving to begin working under his guidance he insisted I was unable/incapable of carrying out remote, petrologic field work as a female student, as 'what would we do with you in the field; it would be so difficult'. After months of discussion with other/male graduate students as well as the professor, I realized he had assumed an incorrect gender for me based on my application, and there was no way I could continue as his student and be funded. He absolutely would not allow me to participate in the science I had been accepted to do.

I left graduate school for 2+ years, and worked; then with eyes wide open applied for admission to PhD programs, and completed one in a different subject with my own funding.

69 I was on a trip in a foreign country and I asked if I could engage in field excursion which involved carrying equipment up a volcano, which two young male-identifying students my age were invited to engage in. I was told that, yes, I could participate and help them carry the equipment up the mountain. Last minute I was called and told there was no need for me to come and participate. There was no explanation, and the two young men grad students were still able to participate in the field work. I work out and I am in good shape physically, and I am trained as an outdoor leader and led outdoor excursions before, but I am a female. I believe it was due a perception about my strength/fitness as a female. I would have had to complain or push my way in to be able to keep that opportunity, and I did not feel it was worth it.

71 1-I regularly publish my researchs. Basing on 30 years of experience, when I have a [specific country] reviewer, I am sure that the paper is rejected. That's why I ask to editor to avoid any [specific country] in editorial process.

77 The list is so long. I think I'll contact you directly. 
79 I have witnessed that a white middle aged successful professor has been bullied by several female junior researchers. Even the professional external help that was involved to solve the conflict has been bias and acted not according to the facts but according to the current believe system.

80 Witnessed several female PhD students being sexually harassed by their male PhD supervisor who retaliated if rebuffed (bad-mouthing to industry contacts, refusal to provide academic supervision/support, etc). By contrast he treated his male PhD students very well.

81 Administration of research: my voice was ingnored, but when a mal said the same think it raised attention. A a woman, I experience that pleople never think of women for responsibilities

82 I'm not ready to share this story yet. The person that has actively discriminated against me throughout my career is a highly active member of the volcanology community, and as an ECR still finding my way onto the academic pyramid, I can't deal with this yet. I hope you get lots of stories though, they need to be told. I also hope you're able to capture some of the discrimination that has been felt my people outside volcanology but at the hands of scientific teams in-country to the local populations.

84 I was a postgraduate acting as a demonstrator on an undergraduate field trip abroad. $H \& S$ rules dictate that a back up car be driven with the coach in case of accidents in the field. Two male lecturers (including the volcanologist this story relates to) and myself were added as drivers to the car. On the first day of the trip the volcanologist said he was too ill to go so I ended up driving the back up car. On the second day I was preparing to drive when I walked up and said that he didn't want me to drive, grabbed the keys out of my hand and forced me out of the drivers seat. We would eat out every evening and the better restaurants needed to be driven to. When I pointed out that the volcanologist didn't want me to drive during the day he said that he had already started drinking alcohol so wasn't able to drive everyone. On the first evening, when we arriving back to the accommodation, he would make disparaging comments about my driving skills. This tension went on all week with no other members of staff dealing with it. There was a tradition on the last night of setting up BBQs for the undergraduates and having a party. I was tired, didn't want to drink and agreed to be the designated emergency driver. Unfortunately there was a medical emergency with a female undergrad. As there were no female members of staff I was not only required to drive but also accompany them to the hospital. We got back at 1.30 am and had to be up at 6 am to travel to the airport. I knew I was tired after dealing with the hospital, the other back up driver was also the field trip leader and had been at the hospital so we wanted the volcanologist to drive. He had drunk so much the night before that he was still over the limit. There were two female undergrads not feeling well so the decision was made that I would drive, with the two other female postgrads and two female undergrads. On the way to the airport we were involved in a hit-and-run. We had to deal with the police before leaving the car and continuing to the airport on the bus. When I got on the bus the volcanologist made a comment about 'female drivers'. Upon our return to the department I was not asked about what had happened, no follow up checks and I was blacklisted from demonstrating on any other field trips. Meanwhile, the volcanologist faced no repercussions, has continued to be promoted within the department, wins medals for his research [and seems unaware his behaviour is problematic]. 
86 I told my male PhD supervisor that I was not intending to stay in academia after my PhD. Later that day, in a meeting with my other (male) supervisor, he asked what my plans were for after my PhD. Before I could respond, the supervisor I had spoken to in the morning answered: "she's leaving academia, she'll get married and have children." Never, in our conversation that morning, had marriage or children been mentioned. That had nothing to do with why I left academia. His comments made me feel that, as a female who was choosing to leave academia, I was part of the problem with the female drop-out rate in academia. I bet he would not have made that comment if a male PhD student said they were leaving academia. And, if I do choose to get married and have children in the future, is that not my choice and my business?

87 Volcanology is not a very diverse field. When asking for support or even advice on entering the field is met by discrimination - i.e people who thought I should not even be considering this field option due to my ethnicity. At conferences I are not taken seriously either people just tend to not bother with you and make you feel as though you don't belong their. For someone who was obsessed with getting into this field I was let down by people who could have supported me.

91 The design and execution of field work is almost always oblivious to the physical and emotional needs of anyone not cis het Male. So bathroom stops or pauses for more private wild bathroom stops have been neglected on trips led by Male leaders, and sometimes women. Seating in vehicles is very very limited which exacerbates my inflammatory disease and prevents movement needed to reduce limb swelling resulting in a lack of mobility. This leads to being left behind on later segments of trip, when I could have participated if accommodations were not dismissed. There are generic but pervasive.

94 While in graduate school, in several courses with the same professor, I answered a question first and correctly, but was told I did not answer the question correctly because the professor didn't listen to my answer and/or assumed I wouldn't know the answer. When the next person (male) answered with the exact same answer, he was told, 'Exactly. That is the answer I was looking for. 'As this was a math answer, it was not subject to interpretation.

96 The [specific-country] volcanology community can be quite cliquey and there seems to be a bit of a culture of funding each other's proposals and those with the right academic "parentage" while displaying a real hostility to outsiders. This includes aggressive critique of conference presentations (including students), overly harsh or personal reviews of proposals and a general lack of respect when talking about other academics between themselves. It also leads to the same people repeatedly being awarded funding. I personally have been accused of knowing nothing about things I have written proposals on and advised to give my proposal to somebody more senior and concentrate on more junior level tasks. There is also very little recognition of the impact of sexual harassment on victims and a general culture of looking the other way. Perpetrators continue to be welcomed in academic settings, including giving oral presentations at conferences, ignoring the impact this has on those they harassed and their ability to participate in those same events.

97 Sexism about the way I dressed and how that wasn't how scientists dressed 
98 Arranging to go on a field trip with a supervision who needed to write a letter to facilitate the transportation who refused to do so without any explanation.

Not being allowed to stay at designated observatory lodgings because it wasn't "fit" for females.

Not being allowed on a field team because I wasn't "sting" enough or "male" to carry equipment.

100 During important meetings, it occurred several times that the options discussed previously with my boss (and on which we both agreed) were rejected publicly by the same boss when i presented them during the meetings

103 In most of the international conferences or events in which I took part, native Englishspeaking people (or those who are comfortable with English) generally don't make any effort for local languages, which from my point of view a major discrimination (especially for students), sometimes underestimated.

Anyway, good luck for your paper!

104 I witnessed a research geologist refer to Indigenous peoples as sqauws. Where I'm from this is a very derogatory term for Indigenous peoples. They may not have known this. An intern and myself were were referred to as incompetent for doing exactly what we were told to do. I'm clinically diagnosed with ADHD and take medication for it. Being called incompetent did nothing but make the imposter syndrome worse.

106 Female graduate adviser openly and often limited male student opportunities, including me personally. She claimed she was "leveling the field," even in public forums.

Complaints were met with threats of career destruction. All of this was in plain sight of administrators. She, of course, was promoted to [a much higher position] while her male students were lucky to survive graduate school. She also openly discriminated against those she thought were from a lower class.

110 I heard 2 teachers speaking about not carrying a woman partner to a fieldwork because she was "annoying" because she was feminist and vegan.

111 In private and in public, I was subjected to work place bullying while studying for my master by a well respected volcanologist. This centred around my metal health and constant belittlement. This only added to my a severe period of depression, which led me to take a year off to recover.

113 This probably not want you want to hear, but the strongest forms of discrimination I have seen are in the form of preferences for women over men in academic jobs and for research funding (which is hard to document, but anecdotally appears to be true).

My institution has institutionalized favoritism for women in administration and promotion and even stipulates that a woman's salary has to be higher than any man's salary of similar academic rank in each university department.

115 I would say I've experienced (and witnessed) subtle forms of discrimination, and it's not always clear the reason. I'm a female in a male-dominated subfield, but some of the 
colleagues I've had trouble with seem fine working with other females. It could be having a non-standard background or not graduating from a well-known program. It could be personality, "culture", or other related characteristics outside the majority culture which I've noticed in others who are treated similarly. By "subtle forms", I mean things that aren't explicit and might not even be intended, such as dismissiveness, patronizing comments/actions, lack of interest, and seemingly endless hurdles to "prove" yourself. I've occasionally tried to address these concerns directly with colleagues or with a supervisor/manager and have usually been brushed off (e.g., 'they didn't mean it', 'they're nice and wouldn't do something like that') or given sympathy with no action or course for change (e.g., 'I'm sorry to hear that. I hope things get better.', 'I'm sorry and will do better next time' (then repeats the same action), 'It's me, not you. There's nothing you can do better.'). For my specific sub-discipline, at least in my country, it feels like it's a club where you have to know the 'right' people, act the "right" way, work on the 'right' topics, etc. to be included in it. Sometimes I think it's simply due an unconscious preference for "people like me". I can't think of any big or explicit incidences, but over years, the small things add up and can eat away at you. I'm pretty much at a point where I feel done with research careers, or at least my field/subfield, because I feel like what I do isn't really valued, that I don't "belong", and that I will always have to fight or do twice as much to get any acknowledgment or be taken seriously.

116 During fieldwork near the [a volcanic] eruption site, my less experienced colleague was harassed by police because he didn't wear helmet (not really needed [at the time]) although we had permits to be at the site. We were forced to leave while other people who were in the same positions as us, but maybe more senior-looking etc were allowed to stay. 